\title{
ANALYTICAL AND COMPARATIVE INVESTIGATION OF PARTICULATE SIZE EFFECT ON SLURRY FLOW CHARACTERISTICS USING COMPUTATIONAL FLUID DYNAMICS
}

\author{
Om Parkash ${ }^{1,2}$, Arvind kumar ${ }^{2}$ and Basant Singh Sikarwar ${ }^{3}$
}

\begin{abstract}
The key issue associated with the industries is the transportation and dumping of solids particulates in the form of slurry at the desired place using long length pipelines. In this perspective, numerical simulation of three-dimensional horizontal slurry pipeline of $0.0549 \mathrm{~m}$ diameter using Eulerian two-phase model with RNG k$\varepsilon$ turbulence closure is carried out. The glass - beads solid particulates having density $\left(\rho=2470 \mathrm{~kg} / \mathrm{m}^{3}\right)$ and slurry concentration varies as $10 \%$ to $50 \%$ (by volume) for velocity ranges of 3-5 $\mathrm{ms}^{-1}$. The computational modeling is done using available commercial software ANSYS Fluent for $125 \mu \mathrm{m}$ and $440 \mu \mathrm{m}$ particulate size at different velocity and concentration range to know their effect on slurry flow characteristics. It is observed that for chosen particulate size pressure drop increases with increase in velocity at all solid concentration range. The pressure drop in slurry for $440 \mu \mathrm{m}$ solid particulates is found higher as compared to the pressure drop of $125 \mu \mathrm{m}$ solid particulates slurry. The percentage change in pressure drop is also reported in the paper due to particulate size effect at all velocity and solid concentration. The obtained results of predicted pressure drop are analytically compared with the available experimental results of literature and are in synchronism with that. A parametric study is carried out with the aim of visualizing and understanding the solid particulate size effect on slurry flow characteristics. Finally, the results of settling solid concentration contour, velocity contour, concentration profiles, velocity profiles and vector representation of concentration/velocity were also predicted for chosen particulates sized slurry.
\end{abstract}

Keywords: 3D Slurry Pipeline, Eulerian Two-Phase Model, Particulate Size, Slurry Concentration, Velocity Distribution, Pressure Drop

\section{INTRODUCTION}

Transportation of solid with water as a carrier has been employed by various industries since several decades. Transportation of solid through pipeline have several advantages such as no traffic, continuous delivery system, no pollution, easier, efficient and economic way of transportation. Due to the several advantages, this mode of transportation has been adopted by many industries such as chemical, food, cement and power plants etc. The solids particulates with carrier liquid transported through pipelines in many industries are coal ash, glass beads, iron ore, copper and zinc tailing, rock and cement materials etc. The particulate size and their concentration in liquid water cause the several damage and deterioration. The slurry consisting solids that cause the erosion at pipe wall and eddy losses in the pipe bend that adds impact on the flow in the pipeline systems. Additionally, due to high concentration of the solid particles, the pipeline may get further blocked that may cause shut down of the transportation system. Thus, solid with water carrier is pumped through long slurry pipeline require an attention which affects the performance and cost of the whole slurry mode transport. Therefore, in order to design the economical and efficient pipeline system for different slurry range and particulates size, it is important to analyse the slurry flow characteristics using available commercial software ANSYS Fluent. Numerous research is available in the literature to calculate the various slurry flow parameters like pressure drop, velocity and concentration measurement etc. However, experimental set up require a long span and quite complex to monitor it in real time. ANSYS Fluent is one of the most used CFD software because of its user-friendly interface. ANSYS Fluent has capability to solve complex fluid flow problems, which is not possible in Solid works flow simulation and Autodesk simulation. Colwell and Shook [1] experimented optimum entry length for the chosen sand and polystyrene slurry and calculated the concentration and velocity distribution at three different position in a This paper was recommended for publication in revised form by Regional Editor Erman Aslan

${ }^{1 *}$ Department of Mechanical Engineering, Amity University Haryana, Gurgaon, India

${ }^{2}$ Department of Mechanical Engineering, JC Bose University of Science and Technology, YMCA, Faridabad, India

${ }^{3}$ Department of Mechanical Engineering, Amity University Uttar Pradesh, Noida, India

*E-mail address: om.mech8@gmail.com, arvind_eem@yahoo.co.in, bssikarwar@amity.edu

Orcid id: 0000-0001-7080-570X, 0000-0003-0495-199X, 0000-0001-8532-7528

Manuscript Received 11 December 2018, Accepted 10 March 2019 
horizontal pipe of $0.50 \mathrm{~m}$ diameter. Turian et al. [2] carried out the experiment and studied the effect of minute glass beads particulates on friction loss in a horizontal pipeline and their findings show that inertial effects are dominated in non-colloidal flow in comparison to colloidal flow. The finding show that the inertial effects are more dominated for non colloidal flow as compared to the minute colloidal flow. Flow pattern of sand slurry in a pipe of $0.105 \mathrm{~m}$ diameter at three different inclinations are analyzed by Matousek [3] in a laboratory experiment. The simulation of coarser particulates in a vertical pipe using k- $\varepsilon$ turbulence closure is done by Krampa-Morlu et. al. [4] and they studied the effect of particulate concentration, size and viscosities. Kaushal et al. [5] experimented near wall lifts for coarser solid particulates in a slurry pipe having diameter of $0.0549 \mathrm{~m}$ and predicted pressure drop for finer particles, and compared it with equivalent fluid and found that the slip velocity effect on pressure drop was more at higher velocity and less at low velocity. Kumar et al. [6] carried out the study by using two layer and Karabelas model and examined the effects of bimodal slurries on slurry pressure drop. The simulation of sand liquid slurry flow using algebraic slip model and constraint growth at the entry unit is done by Lin and Ebadian [7]. Pressure drop and rheological characteristics of the fly-ash slurry is studied by Chandel et al. [8] and their findings show that the slurry does not experience any settling at all test conditions. Further, he performed the experiment on Pilot plant test loop with/without additives in fly ash slurry and found a fall in pressure drop on addition of additive [9].

Furthermore, Naik et al. [10] study slurry rheological characteristics at different temperature using cationic surfactant and counter ion. They observed that the suspension stability and dispersing capability of the particulate were improved on addition of counter and cationic ion. Senapati et al. [11] implemented the power law fluid and studied the effect of fly-ash slurry on friction. Afterwards, Jiang and Zhang [12] carried out the numerical simulations using k- $\varepsilon$ turbulence model on slush nitrogen flow in horizontal pipe of $0.015 \mathrm{~m}$ diameter and length $1.5 \mathrm{~m}$. Their findings show that computational time taken for solving 3D model was more in comparison to 2D model. Kaushal et al. [13] simulated flow of mono-dispersed particulate at high concentration using Eulerian and mixture models in a pipe of $0.0549 \mathrm{~m}$ diameter. It has been found that Eulerian model gives better results for pressure drop as compared to the mixture model. Later, they experimented mixture of fly ash at high concentration on Pilot plant test loop and projected the rheological characteristics of slurry. The optimum concentrations of flyash slurries is found to be $65 \%$ (by weight) on the basis of specific energy consumptions [14]. Nabil et al. [15] predicted the sand-water slurry flow characteristics in a pipeline for three particulate sizes of 0.0002, 0.0007 and $0.0014 \mathrm{~m}$ in a velocity range of 0.5 to $5 \mathrm{~ms}-1$. The results shows that the irregularities rises with increase in particles size because of gravity. Silva et al. [16] studied velocity effect and the settling characteristics of slurry flow. Gopaliya and Kaushal [17] studied the effect of particulate size on pressure drop and found that the pressure drop increases with increase in particulate size at all efflux concentration. Pani et al. [18] studied the additives effect on the rheological behaviour of coal ash slurry. Assefa and Kaushal [19] carried out the experiment by adding the fly ash slurry in the bottom ash slurry and evaluated the rheological characteristics that results the decrease in yield stress and viscosity of the slurry. Later, the CFD simulation of sand water flow in a horizontal pipeline was by Swamy et al. [20]. In their study, they predicted that large sized particulates exhibits heterogeneous flow. Gopaliya and Kaushal [21] simulated sand water slurry flow in a pipe of $0.263 \mathrm{~m}$ diameter and found that the velocity profile is symmetric and asymmetric in nature for fine and coarse particles respectively. Ofei and Ismail [22] predicted the frictional pressure drop for different particulate size and obtained outcomes show that pressure drop decreases with increase in particle sizes. Melorie and Kaushal [23] experimented that the addition of hydrated lime as a chemical additives in an iron ore slurry increases the yield stress for the chosen concentration range. Naveh et al [24] predicted pressure drop through various turbulence models for diluted slurry in a horizontal pipe and found that pressure drop is a strong function of Archemede's number. Singh et al. [25] predicted the flow characteristics of ash - water flow in a pipe of $0.050 \mathrm{~m}$ diameter using Eulerian- Lagrange SST K- $\omega$ turbulence model for a wide range of velocity and solid concentrations. The simulated outcomes show nonlinear rise in pressure drop with increase in velocity and solid concentration. Mohanty et al. [26-27] carried out the numerical simulation of counter flow heat exchanger and predicted the flow characteristics. Some of the recent work on slurry pipeline for obtaining the slurry flow characteristics is done by Parkash et al. [28-33]. Arora et al. [34-35] optimized the irreversible engine using ecological criteria. Further, Dalkiliç et al. [36-37] conducted the computational analysis of smooth pipe for the prediction of Nusslet number, and smoke and temperature investigation with the help of jet fan. 
In the literature, numerous experimental and theoretical studies are available on slurry pipeline using different flow materials like fly ash, bottom ash and silica sand etc. There is no literature available for the numerical simulation of glass beads particulate size and their size effect on slurry flow characteristics. Therefore, it is important to study the particulate size effect on slurry flow characteristics i.e. concentration distribution, velocity distribution and pressure drop. In this paper, a parametric study is carried out to know the effect of solid particulate size on slurry flow characteristics. Nevertheless, it is observed that the experimental determination of slurry flow parameters at different location in the pipeline is quite difficult and time consuming task. Henceforth, computational fluid dynamics possess ample scope and capability for evaluating above-mentioned constraints at any section of the pipeline. In this paper, an attempt has been made to develop a computational model for prediction of concentration, velocity and pressure drop profiles for glass beads particulate size of $125 \mu \mathrm{m}$ and 440 $\mu \mathrm{m}$ using Eulerian two-phase model with RNG k- $\varepsilon$ turbulence closure. The computational modeling of $0.0549 \mathrm{~m}$ diameter pipeline has been carried out for a wide range of solid concentration ranging $10 \%$ to $50 \%$ (by volume) with wide velocity span of 3-5 ms-1. The obtained simulated outcomes are verified with the experimental results of the literature and found in synchronism with that.

\section{MATHEMATICAL MODEL}

In this paper, an efficient Eulerian-Eulerian multi-phase model is implemented for numerical simulation. The following governing equations are used for the turbulent flow of glass beads slurry flow.

\section{Eulerian model}

Eulerian two - phase model is used as this model comprises the complex equations of multiphase modelling in ANSYS Fluent software. It solve the set of continuity and momentum equations for each phase. In Eulerian model, the slurry is assumed to be comprised of solid $\left(\alpha_{s}\right)$ and liquid $\left(\alpha_{f}\right)$ phases i.e. $\alpha_{s}+\alpha_{f}=1$. In the present model granular flow have been consists of solid and liquid phase mixing that is achieved by interphase exchange and pressure exchange coefficients. Additionally kinetic theory application is used for deriving the slurry flow characteristics. The forces acting on the particulates in the slurry flow and various assumptions undertaken are given below:

1. Static/solid pressure gradients, $\nabla \mathrm{P} / \nabla \mathrm{Ps}$.

2. Forces due to the difference in velocities of two phases, $K_{s f}\left(\vec{v}_{s}-\vec{v}_{f}\right)$

3. Viscous and body forces, $\nabla \overline{\overline{\tau_{f}}}$ and $\rho \overrightarrow{\mathrm{g}}$, where $\overline{\overline{\tau_{f}}}$ represents the stress fluid, $\rho$ denotes the mass density and $\mathrm{g}$ is gravitational acceleration.

4. Lift/virtual mass forces. The coefficient of virtual mass/ lift forces, $\mathrm{C}_{\mathrm{L}} / \mathrm{C}_{\mathrm{vm}}$ are assumed to be 0.5 .

5. The solid particulates is assumed to be of spherical in shape and fluidic in nature.

6. The 3D pipe geometry with negligible thickness is considered in the computational domain.

7. The roughness constant of the wall is assumed as 0.5

\section{Governing equations}

The following governing equations are used for the turbulent flow of glass beads slurry flow. The continuity and momentum equation for each phase is defined as [14]:

\section{Continuity Equation}

Here, $t$ can be considered as for $s$.

$$
\nabla \cdot\left(\alpha_{t} \rho_{t} \vec{v}_{t}\right)=0
$$

Momentum Equations for fluid and solid phases

For Fluids:

$$
\begin{gathered}
\nabla .\left(\alpha_{f} \rho_{f} \vec{v}_{f} \vec{v}_{f}\right)=-\alpha_{f} \nabla P+\nabla\left(\overline{\overline{\tau_{f}}}+\overline{\bar{\tau}}_{t, f}\right)+\left(\alpha_{f} \rho_{f} \vec{g}\right)+K_{s f}\left(\vec{v}_{s}-\vec{v}_{f}\right)+ \\
C_{v m} \alpha_{s} \rho_{f}\left(\vec{v}_{s} \cdot \nabla \vec{v}_{s}-\vec{v}_{f} \cdot \nabla \vec{v}_{f}\right)+C_{L} \alpha_{s} \rho_{f}\left(\vec{v}_{f}-\vec{v}_{s}\right)^{\times}\left(\nabla^{\times} \vec{v}_{f}\right)
\end{gathered}
$$


For Solids:

$$
\begin{gathered}
\nabla .\left(\alpha_{s} \rho_{s} \vec{v}_{s} \vec{v}_{s}\right)=-\alpha_{s} \nabla P-\nabla P_{s}+\nabla\left(\overline{\bar{\tau}}_{s}+\overline{\bar{\tau}}_{t, f}\right)+\left(\alpha_{s} \rho_{s} \vec{g}\right)+K_{f s}\left(\vec{v}_{f}-\vec{v}_{s}\right)+ \\
C_{v m} \alpha_{s} \rho_{f}\left(\vec{v}_{f} \cdot \nabla \vec{v}_{f}-\vec{v}_{s} \cdot \nabla \vec{v}_{s}\right)+C_{L} \alpha_{s} \rho_{f}\left(\vec{v}_{s}-\vec{v}_{f}\right)^{\times}\left(\nabla \times \vec{v}_{f}\right)
\end{gathered}
$$

Where,

$$
\begin{gathered}
\overline{\overline{\tau_{s}}}=\alpha_{s} \mu_{s}\left(\nabla \vec{v}_{s}+\nabla \vec{v}_{s}^{t r}\right)+\alpha_{s}\left(\lambda_{s}-\frac{2}{3} \mu_{s}\right) \nabla \vec{v}_{s} \overline{\bar{I}} \\
\overline{\overline{\tau_{f}}}=\alpha_{f} \mu_{f}\left(\nabla \vec{v}_{f}+\nabla \vec{v}_{f}^{t r}\right) \\
\lambda_{s}=\frac{4}{3} \alpha_{s} \rho_{s} d_{s} g_{\text {o.ss }}\left(\left(1+e_{s s}\right)\left(\frac{\Theta_{s}}{\Pi}\right)^{1 / 2}\right)
\end{gathered}
$$

$d_{p}$ is the diameter of the particulates which is taken as $125 \mu \mathrm{m}$ and $440 \mu \mathrm{m}$ in the present study.

\section{Solid Shear Viscosity}

The shear viscosity $\mu_{\mathrm{s}}$ is given as:

$$
\mu_{s}=\mu_{s, c o l}+\mu_{s, k i n}+\mu_{s, f r}
$$

Where,

$$
\mu_{s, c o l}=\frac{4}{5} \alpha_{s} \rho_{s} d_{s} g_{o . s s}\left(\left(1+e_{S S}\right)\left(\frac{\Theta_{s}}{\Pi}\right)^{1 / 2}\right)
$$

Where,

$$
\begin{gathered}
\Theta_{S}=\frac{K \Theta_{s}}{\gamma} \frac{\partial \Theta_{s}}{\partial n}+\frac{\sqrt{3} \pi \emptyset \alpha_{s} g_{o . s s} \Theta_{s}^{3 / 2} v_{s}^{2}}{6 \alpha_{s, \max } \gamma} \\
\mu_{s, f r}=\frac{P_{S} \sin \varphi}{\sqrt[2]{I_{2 D}}} \\
\mu_{s, k i n}=\frac{\alpha_{s} \rho_{s} d_{s \sqrt{\pi \Theta_{S}}}}{6\left(3-e_{s S}\right)}\left[1+\frac{2}{5}\left(1+e_{s S}\right)\left(3 e_{s s}-1\right) \alpha_{s} g_{o . s s}\right]
\end{gathered}
$$

The inter-phasial momentum exchange coefficient, $\mathrm{K}_{\mathrm{sf}}$ is given as:

$$
K_{s f}=K_{f s}=\frac{3}{4} \frac{\alpha_{s} \alpha_{f} \rho_{f}}{V_{r, s}^{2} d_{s}} C_{D}\left(\frac{R e_{s}}{V_{r, s}}\right)\left|\vec{v}_{s}-\vec{v}_{f}\right|
$$

The drag coefficient, $\mathrm{C}_{\mathrm{D}}$ is given as:

$$
C_{D}=\left[0.63+4.8\left(\frac{R e_{s}}{V_{r, s}}\right)^{-1 / 2}\right]^{2}
$$

$R e_{s}$ is the relative Reynolds number for the liquid and solid phase and defined as:

$$
R e_{S}=\frac{d_{s} \rho_{l}\left(\vec{v}_{s}-\vec{v}_{f}\right)}{\mu_{l}}
$$




\section{Wall function}

The standard wall function proposed by Launder and Spalding (1983) has been employed in the present work [32]. The chosen wall function provides more accurate and meticulous results for both solid and liquid phases using Eulerian two-phase model.

\section{COMPUTATIONAL DOMAIN AND GRID INDEPENDENT TEST}

The computational mesh for 3D slurry pipeline of length $3.8 \mathrm{~m}$ and diameter $0.0549 \mathrm{~m}$ is generated in ANSYS 16. The computational pipe length is more than 50 diameters, which is sufficiently long for fully developed flow. The mesh contains $462 \mathrm{~K}$ hexahedral and quad type cells. Figure 1(b) depicts the grid independent test performed by using different grid geometry containing $154 \mathrm{~K}, 243 \mathrm{~K}, 382 \mathrm{~K}, 462 \mathrm{~K}$ and $522 \mathrm{~K}$ hexahedral and quad elements at $C_{v f}=10 \%$ and $V_{m}=5 \mathrm{~ms}^{-1}$. It is seen that the results are overlapping for the grid geometry containing $462 \mathrm{~K}$ and $522 \mathrm{~K}$ cells. Hence, a grid with $462 \mathrm{~K}$ cells is preferred for the simulation of slurry flow as shown in the Figure 1 (a).

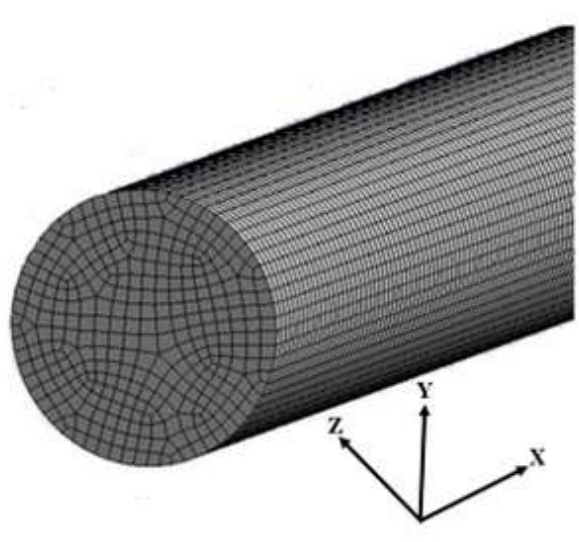

(a)

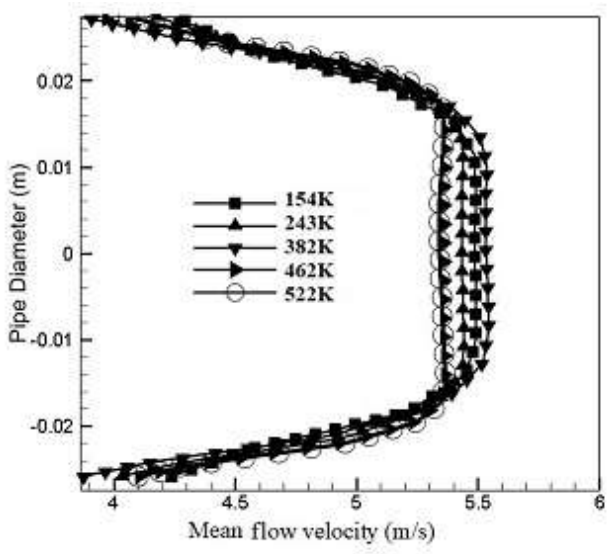

(b)

Figure 1. (a) Mesh in computational domain and (b) velocity profile with respect to radial distance at $V_{m}=5 \mathrm{~ms}^{-1}$ and $C_{v f}=40 \%$

\section{Boundary conditions}

The computational 3D pipeline geometry is bounded by three faces viz. inlet, outlet and wall boundaries to achieve fluid domain calculations. The velocity inlet, pressure outlet and no slip conditions has been applied for the computational domain. The boundary condition at inlet is applied at particular velocity and solid volume fraction. Pressure outlet is applied at the pipe outlet. The no slip conditions has been considered at the pipe wall.

\section{Solution strategies and convergence criteria}

A second order upwind scheme is used to simplify the momentum, turbulence kinetic energy and fluid flow equations. This arrangement offers high precision, reliability and converging of the solutions. The converging condition based on residual value of various constraints viz. mass, turbulent kinetic, velocity, dissipation energy and volume fractions. In the present model, the value is reset to 0.001 time the initial residual values for every constraint as a converging criteria. Coupling between velocity and pressure is achieved by using semi-implicit pressure linked equations (SIMPLE) algorithm. The other solution strategy includes the under relaxation factors of pressure -0.3 , momentum -0.5 , volume fraction -0.5 , turbulent viscosity -0.8 , turbulent kinetic/dissipation energies as 0.8 . This converges the non-linear equations into linear ones.

\section{COMPUTATIOANL RESULTS \\ Solid concentration contours}

Figures (2-7) depict the settling behavior of solid particulate size $125 \mu \mathrm{m}$ and $440 \mu \mathrm{m}$ for chosen range of velocity $\left(V_{m}=3-5 \mathrm{~ms}^{-1}\right)$ at different solid concentration ranging from $10 \%-50 \%$ (by volume) at pipe outlet. It has been observed that the small sized particulates shift towards the pipe bottom as depicted in the Figure (2),(4) and (6), whereas large sized particulates shift away from the pipe bottom as depicted in the Figure (3), (5) and (7). The reason behind shifting the large sized particulates is due to the increase of near wall lift force employed during 
the simulation. Figure 2(a-e) depicts the solid concentration contours at $V_{m}=3 \mathrm{~ms}^{-1}$ for $125 \mu \mathrm{m}$ particulate size and it has been observed that increase in solid concentration contribute to the exchange of momentum with the solids that enhance the turbulence mixing and spreading of the solid particulates in the pipeline. Figure 2(a-d) depicts that solid concentration is found maximum at the bottom and minimum at the top of the pipe. However, Figure 2(e) depicts that at $C_{v f}=50 \%$, the increased momentum exchange and turbulence mixing disperse the solids in the pipe domain and maximum solid concentration found near the wall. Similar trend we can observe at different solid concentration in the subsequent Figures 4(a-e) and 6(a-e) at higher mean flow velocity $V_{m}=4-5$ ms-1 for $125 \mu \mathrm{m}$ particulate size. Figure 3(a-d) depicts the solid concentration is found maximum away from the pipe bottom and below from the centre of the pipe. However, at $C_{v f}=50 \%$ the solids disperse in the pipe domain due to increased momentum exchange and turbulence mixing that shifts the solids about the pipe centre as depicted in the Figure 3(e). Similar trend we can observe at different solid concentration in the subsequent Figures 5(a-e) and 7(a-e) at higher mean flow velocity, $V_{m}=4-5 \mathrm{~ms}^{-1}$ for $440 \mu \mathrm{m}$ particulate size.

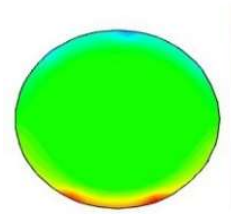

(a)

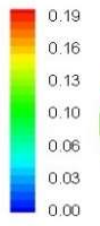

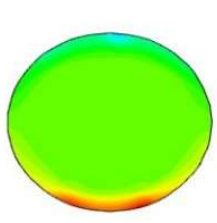

(b)
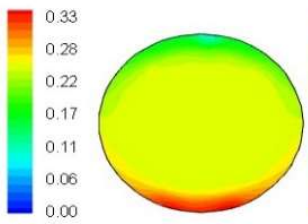

(c)

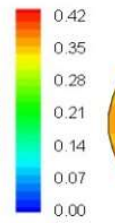

(d)

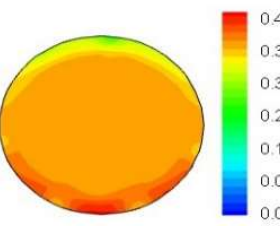

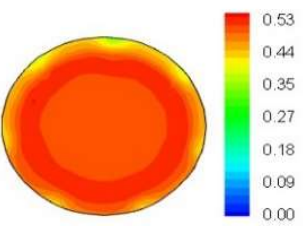

(e)

Figure 2. Solid concentration at $V_{m}=3 \mathrm{~ms}^{-1}$ for particulate size $\mathrm{d}_{\mathrm{p}}=125 \mu \mathrm{m}$ at (a) $C_{v f}=10 \%$, (b) $C_{v f}=20 \%$, (c) $C_{v f}=30 \%$, (d) $C_{v f}=40 \%$, and (e) $C_{v f}=50 \%$

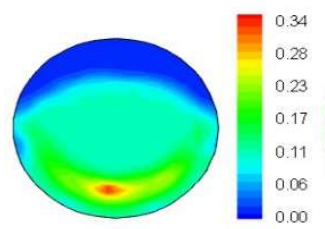

(a)

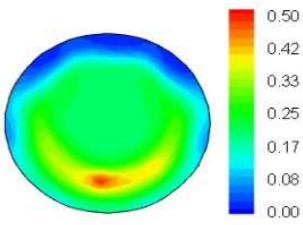

(b)

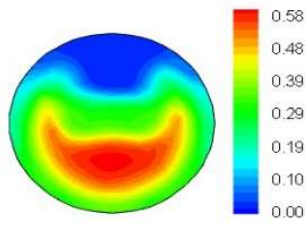

(c)

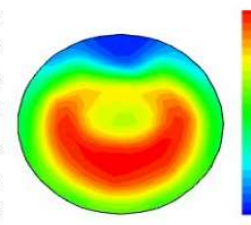

(d)

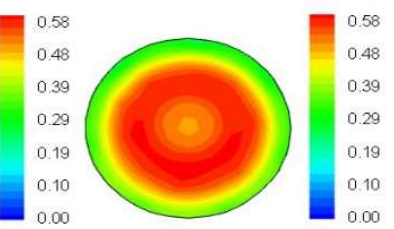

(e)

Figure 3. Solid concentration at $V_{m}=3 \mathrm{~ms}^{-1}$ for particulate size $\mathrm{d}_{\mathrm{p}}=440 \mu \mathrm{m}$ at (a) $C_{v f}=10 \%$, (b) $C_{v f}=20 \%$, (c) $C_{v f}=30 \%$, (d) $C_{v f}=40 \%$, and (e) $C_{v f}=50 \%$

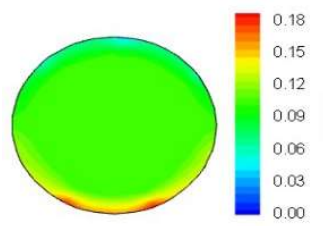

(a)

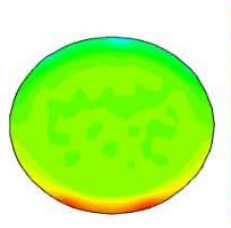

(b)
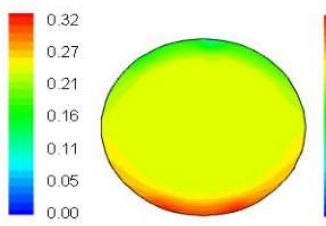

(c)
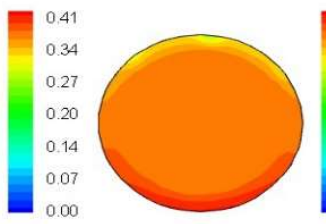

(d)

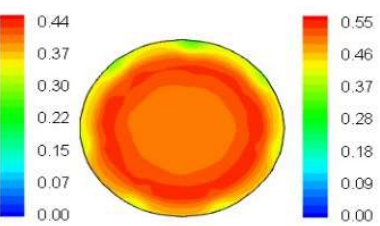

(e)

Figure 4. Solid concentration at $V_{m}=4 \mathrm{~ms}^{-1}$ for particulate size $\mathrm{d}_{\mathrm{p}}=125 \mu \mathrm{m}$ at (a) $C_{v f}=10 \%$, (b) $C_{v f}=20 \%$, (c) $C_{v f}=30 \%$, (d) $C_{v f}=40 \%$, and (e) $C_{v f}=50 \%$

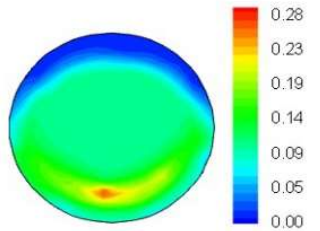

(a)

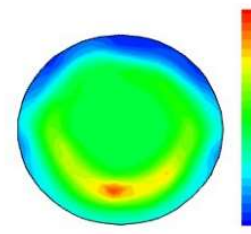

(b)
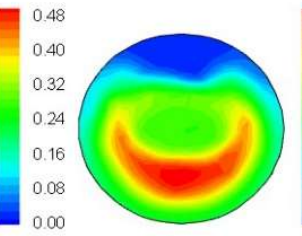

(c)
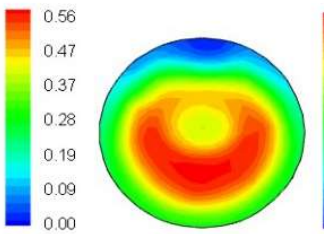

(d)

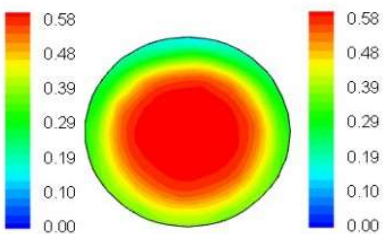

(e)

Figure 5. Solid concentration at $V_{m}=4 \mathrm{~ms}^{-1}$ for particulate size $\mathrm{d}_{\mathrm{p}}=440 \mu \mathrm{m}$ at (a) $C_{v f}=10 \%$, (b) $C_{v f}=20 \%$, (c) $C_{v f}=30 \%$, (d) $C_{v f}=40 \%$, and (e) $C_{v f}=50 \%$

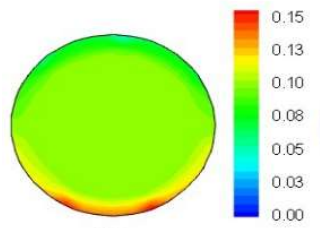

(a)

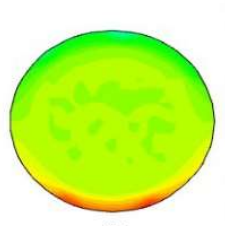

(b)
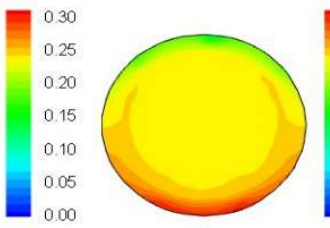

(c)
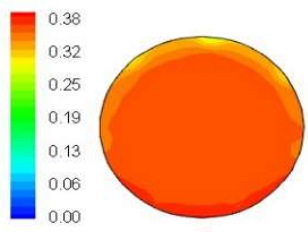

(d)

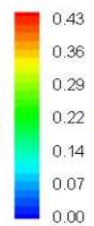

0.00

(e)

Figure 6. Solid concentration at $V_{m}=5 \mathrm{~ms}^{-1}$ for particulate size $\mathrm{d}_{\mathrm{p}}=125 \mu \mathrm{m}$ at (a) $C_{v f}=10 \%$, (b) $C_{v f}=20 \%$, (c) $C_{v f}=30 \%$, (d) $C_{v f}=40 \%$, and (e) $C_{v f}=50 \%$ 


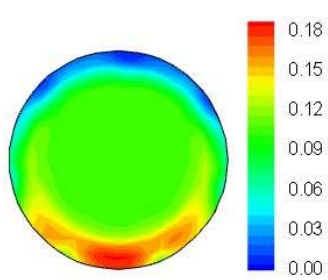

(a)

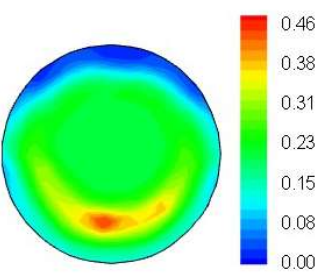

(b)

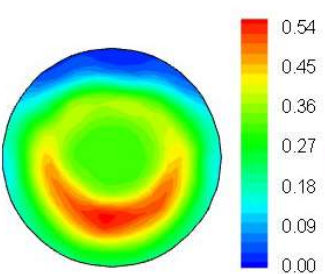

(c)

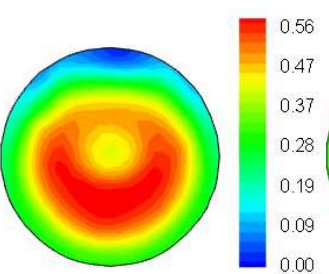

(d)

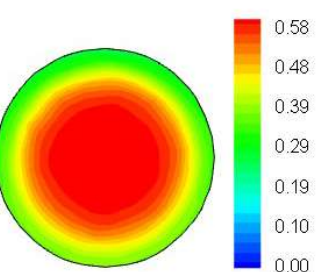

(e)

Figure 7. Solid concentration at $V_{m}=5 \mathrm{~ms}^{-1}$ for particulate size $\mathrm{d}_{\mathrm{p}}=440 \mu \mathrm{m}$ at (a) $C_{v f}=10 \%$, (b) $C_{v f}=20 \%$, (c) $C_{v f}=30 \%$, (d) $C_{v f}=40 \%$, and (e) $C_{v f}=50 \%$

\section{Solid velocity contours}

Figures (8-13) depict the velocity contours of solid particulate size $125 \mu \mathrm{m}$ and $440 \mu \mathrm{m}$ at different solid concentration ranging from $10 \%-50 \%$ (by volume) at pipe outlet. In general, it found that both solid particulate exhibits maximum velocity at the centre of the pipe and minimum at the pipe wall. The minimum velocity exhibits at the pipe wall due to the effect of shear forces. Figure 8(a-e) depicts the solid velocity contours at mean flow velocity, $V_{m}=3 \mathrm{~ms}^{-1}$ for $125 \mu \mathrm{m}$ solid particulates and it is found that solid contours are symmetrical about the centre of the pipe. For $125 \mu \mathrm{m}$ solid particulates, the velocity contours are symmetrical about the pipe centre because of its more dispersal/spreading tendency in the slurry at all velocity range and solid concentration. Similar effect can also be observed at higher mean flow velocity, $V_{m}=4-5 \mathrm{~ms}^{-1}$ for different solid concentration range in the subsequent Figures 10(a-e) and 12(a-e). However, the velocity contours are varying and show symmetrical/asymmetrical behaviour for $440 \mu \mathrm{m}$ solid particulates at different velocity and solid concentration range. For $440 \mu \mathrm{m}$ solid particulates, the solid velocity contour are symmetrical at low velocity $\left(V_{m}=3-5 \mathrm{~ms}^{-1}\right)$ and low solid concentration $\left(C_{v f}=10-20 \%\right)$ as depicted in the Figure 9(a-b) and 11(a-b). The velocity contours are also symmetrical at low velocity $\left(V_{m}=3-5 \mathrm{~ms}^{-1}\right)$ and higher solid concentration $\left(C_{v f}=50 \%\right)$ due to increased momentum and turbulence as depicted in the Figure $9(\mathrm{e})$ and 11(e). The velocity contours becomes asymmetrical at low velocity $\left(V_{m}=3-4 \mathrm{~ms}^{-1}\right)$ and for solid concentration range $\left(C_{v f}=30-40 \%\right)$ as depicted in the Figure $9(\mathrm{c}-\mathrm{d})$ and 11 (c-d). However, the velocity contours are symmetrical about the pipe centre at high velocity, $V_{m}=5 \mathrm{~ms}^{-1}$ for all solid concentration range, $C_{v f}=10-50 \%$ because of increased turbulence at higher velocity that increase the dispersal/spreading of solid particulates in the slurry as depicted in the Figure 13(a-e).

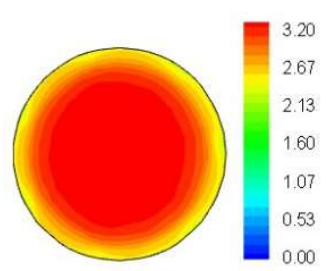

(a)

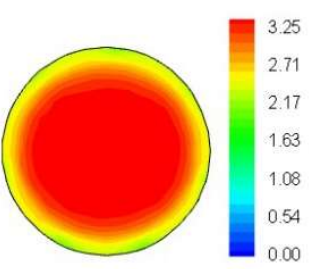

(b)

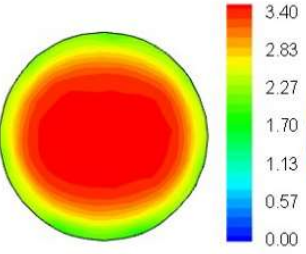

(c)

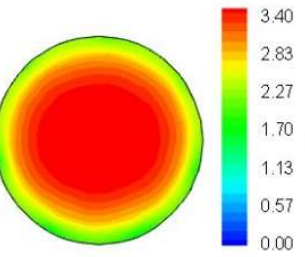

(d)

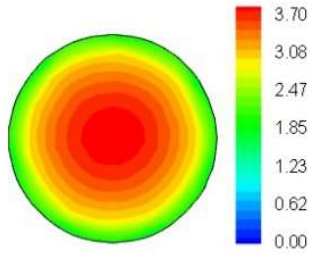

(e)

Figure 8. Solid velocity at $V_{m}=3 \mathrm{~ms}^{-1}$ for particulate size $\mathrm{d}_{\mathrm{p}}=125 \mu \mathrm{m}$ at (a) $C_{v f}=10 \%$, (b) $C_{v f}=20 \%$, (c) $C_{v f}=30 \%$, (d) $C_{v f}=40 \%$, and (e) $C_{v f}=50 \%$

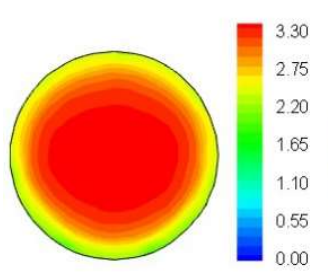

(a)

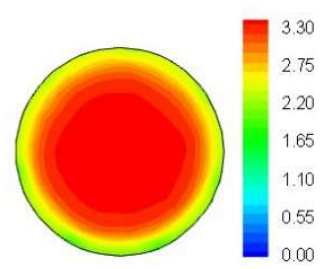

(b)

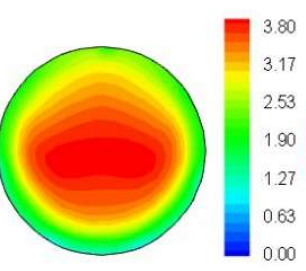

(c)

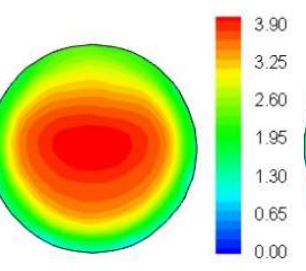

(d)

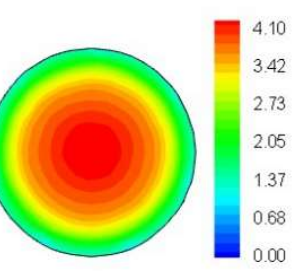

(e)

Figure 9. Solid velocity at $V_{m}=3 \mathrm{~ms}^{-1}$ for particulate size $\mathrm{d}_{\mathrm{p}}=440 \mu \mathrm{m}$ at (a) $C_{v f}=10 \%$, (b) $C_{v f}=20 \%$, (c) $C_{v f}=30 \%$, (d) $C_{v f}=40 \%$, and (e) $C_{v f}=50 \%$ 


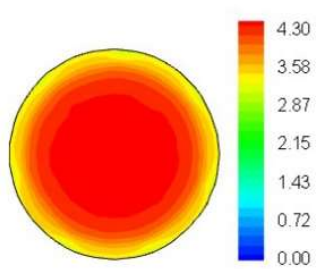

(a)

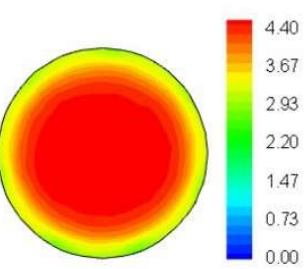

(b)

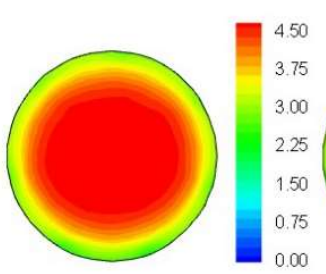

(c)

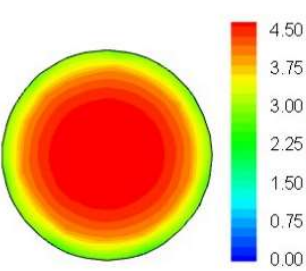

(d)

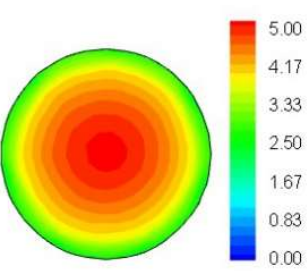

(e)

Figure 10. Solid velocity at $V_{m}=4 \mathrm{~ms}^{-1}$ for particulate size $\mathrm{d}_{\mathrm{p}}=125 \mu \mathrm{m}$ at (a) $C_{v f}=10 \%$, (b) $C_{v f}=20 \%$, (c) $C_{v f}=30 \%$, (d) $C_{v f}=40 \%$, and (e) $C_{v f}=50 \%$

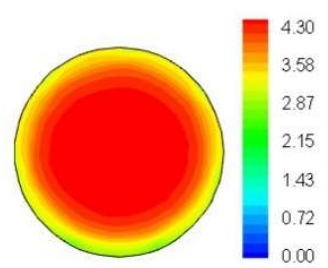

(a)

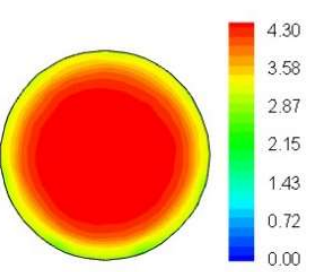

(b)

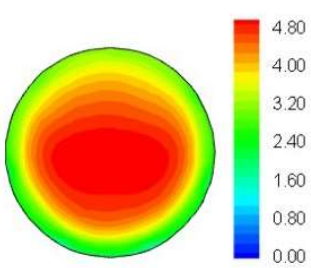

(c)

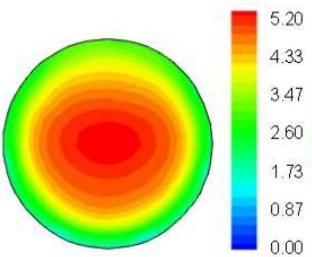

(d)

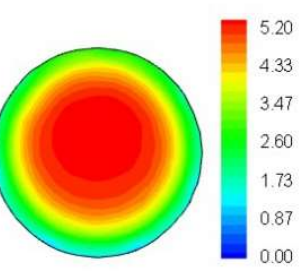

(e)

Figure 11. Solid velocity at $V_{m}=4 \mathrm{~ms}^{-1}$ for particulate size $\mathrm{d}_{\mathrm{p}}=440 \mu \mathrm{m}$ at (a) $C_{v f}=10 \%$, (b) $C_{v f}=20 \%$, (c) $C_{v f}=30 \%$, (d) $C_{v f}=40 \%$, and (e) $C_{v f}=50 \%$

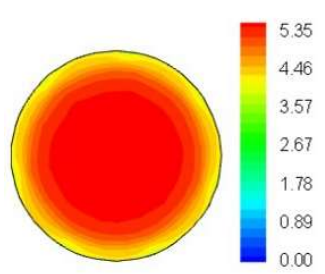

(a)

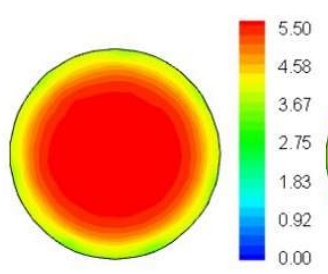

(b)

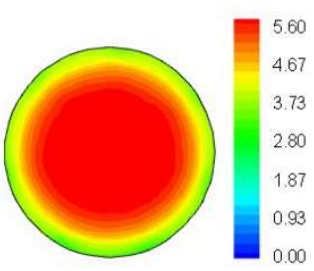

(c)

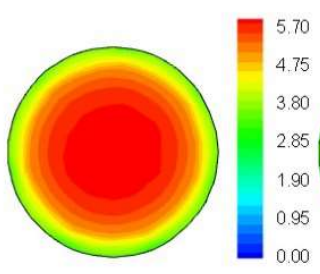

(d)

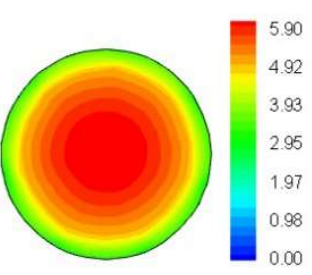

(e)

Figure 12. Solid velocity at $V_{m}=5 \mathrm{~ms}^{-1}$ for particulate size $\mathrm{d}_{\mathrm{p}}=125 \mu \mathrm{m}$ at (a) $C_{v f}=10 \%$, (b) $C_{v f}=20 \%$, (c) $C_{v f}=30 \%$, (d) $C_{v f}=40 \%$, and (e) $C_{v f}=50 \%$

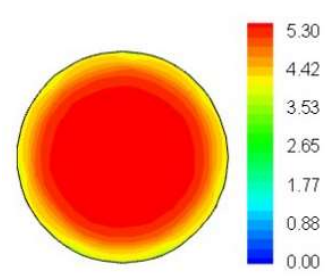

(a)

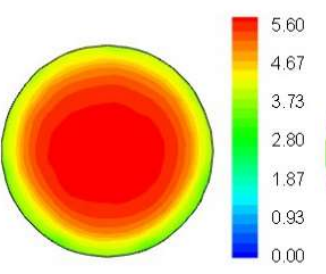

(b)

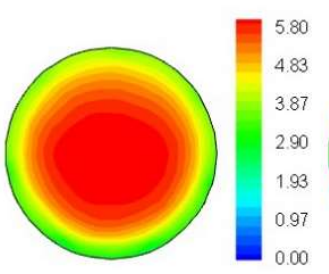

(c)

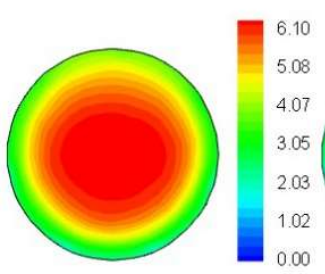

(d)

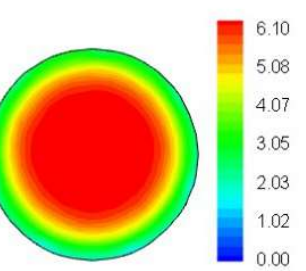

(e)

Figure 13. Solid velocity at $V_{m}=5 \mathrm{~ms}^{-1}$ for particulate size $\mathrm{d}_{\mathrm{p}}=440 \mu \mathrm{m}$ at (a) $C_{v f}=10 \%$, (b) $C_{v f}=20 \%$, (c) $C_{v f}=30 \%$, (d) $C_{v f}=40 \%$, and (e) $C_{v f}=50 \%$

\section{Solid concentration profiles}

Figures (14-16) (a-e) depict the solid concentration profile in XY plane at $(\mathrm{x}=3.7 \mathrm{~m})$ from pipe inlet at different mean flow velocity, $V_{m}=3-5 \mathrm{~ms}^{-1}$ and solid concentration, $C_{v f}=10-50 \%$. In general, it is found that solid concentration decreases from bottom to top of the pipe for chosen particulate size at all velocity and solid concentration range. For $125 \mu \mathrm{m}$ solid particulates, the solid concentration is maximum at the pipe bottom and then decreases radially to the top of the pipe as depicted in the Figure (a-d). However, at $C_{v f}=50 \%$ the solid concentration is maximum away from the pipe bottom and then decreases radially to the top of the pipe as depicted in the Figure 14(e). For $440 \mu \mathrm{m}$ solid particulates, the solid concentration zone is situated away from the pipe bottom in the lower half section of the pipe and then decreases radially from bottom to top of the pipe as depicted in the Figure 14(a-e). Similar effects can also be observed in the subsequent Figures 15(a-e) and 16 (a-e). 


\section{Solid velocity profiles}

Figures (17-19) (a-e) depict the solid velocity profiles in XY plane at $(\mathrm{x}=3.7 \mathrm{~m})$ from pipe inlet at different mean flow velocity, $V_{m}=3-5 \mathrm{~ms}^{-1}$ and solid concentration range, $C_{v f}=10-50 \%$. In general, the maximum velocity is found at the centre of the pipe at all mean flow velocity and solid concentration for chosen solid particulate size. It is found that for the solid concentration range $\left(C_{v f}=10-40 \%\right)$ the velocity profile is flatten in nature for $125 \mu \mathrm{m}$ particulates as depicted in Figure 17(a-d), which in turn becomes parabolic in nature at $C_{v f}=$ $50 \%$ as depicted in the Figure 17(e). Whereas, for large sized $440 \mu \mathrm{m}$ solid particulates the velocity profile is flatten in nature for the solid concentration range, $C_{v f}=10-20 \%$ as depicted in the Figure 17(a-b), which in turn becomes parabolic in nature for the solid concentration range, $C_{v f}=30-50 \%$ as depicted in the Figure 17 (c-e). Similar effects for both the particulate size at different velocity and solid concentration can also be observed in the subsequent Figures 18(a-e) and 19 (a-e). It has been noticed that the behaviour of both solid particulates, at mean flow velocity, $V_{m}=3-5 \mathrm{~ms}^{-1}$ and low solid concentration range, $C_{v f}=10-20 \%$ is nearly same.

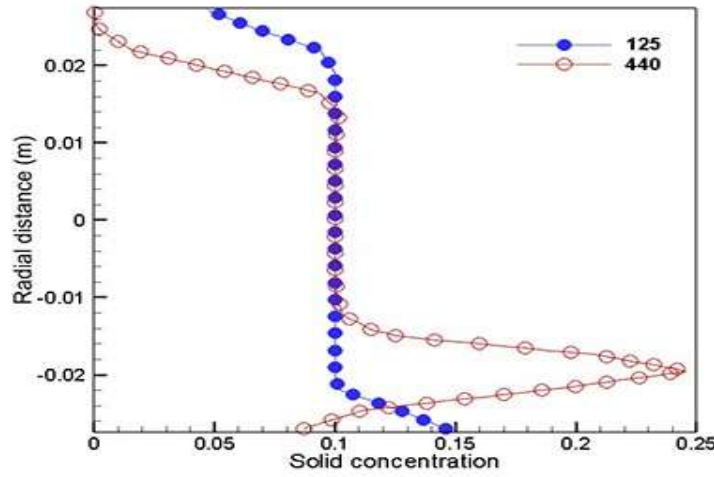

(a)

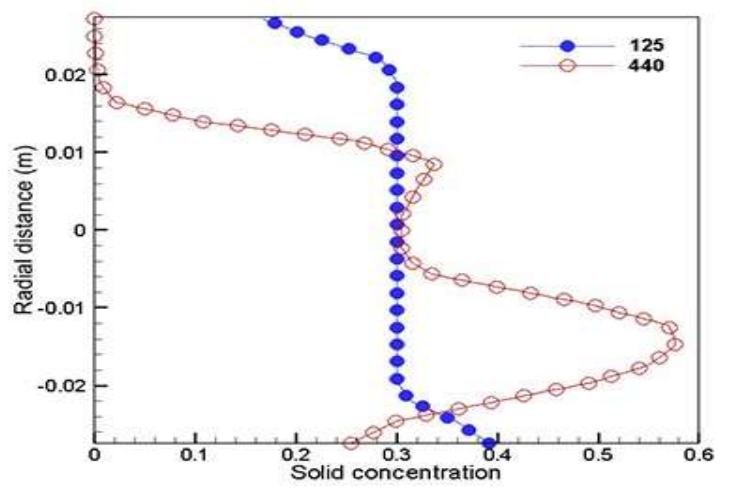

(c)

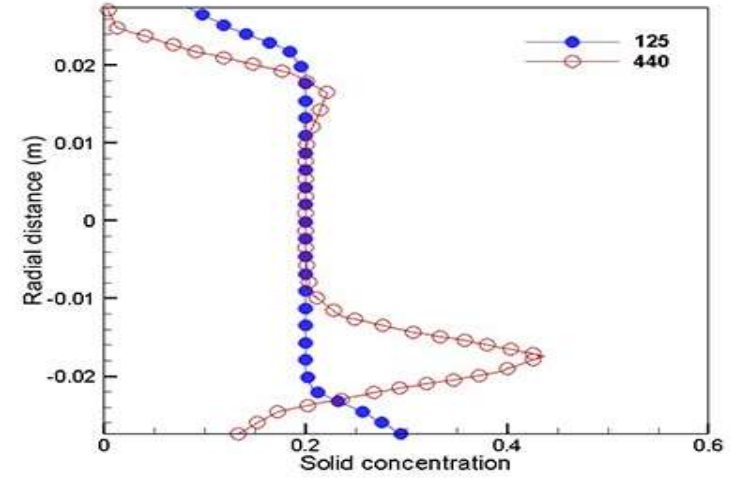

(b)

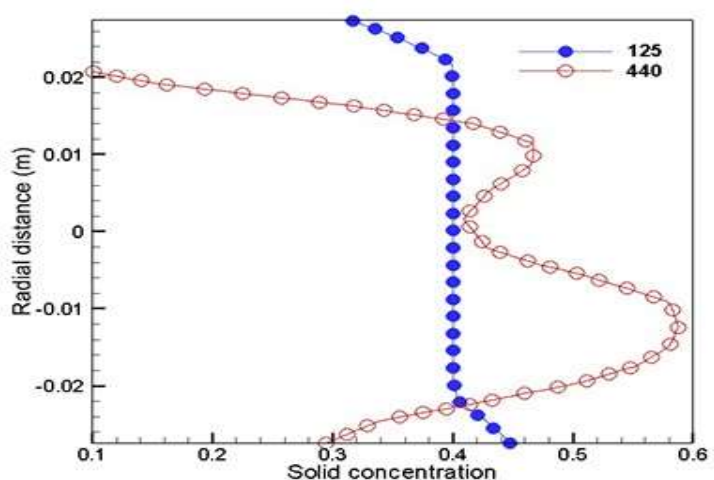

(d)

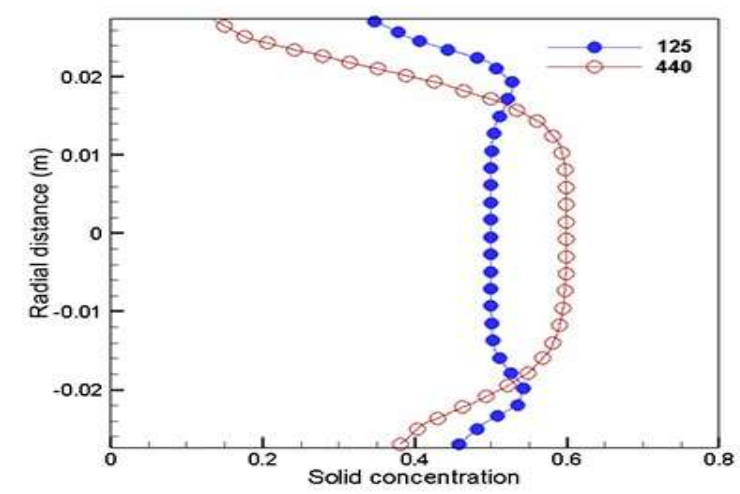

(e)

Figure 14. Solid concentration profiles in XY plane at $\mathrm{X}=3.7 \mathrm{~m}$ and $V_{m}=3 \mathrm{~ms}^{-1}$ (a) $C_{v f}=10 \%$, (b) $C_{v f}=20 \%$, (c) $C_{v f}=30 \%$, (d) $C_{v f}=40 \%$, and (e) $C_{v f}=50 \%$ 


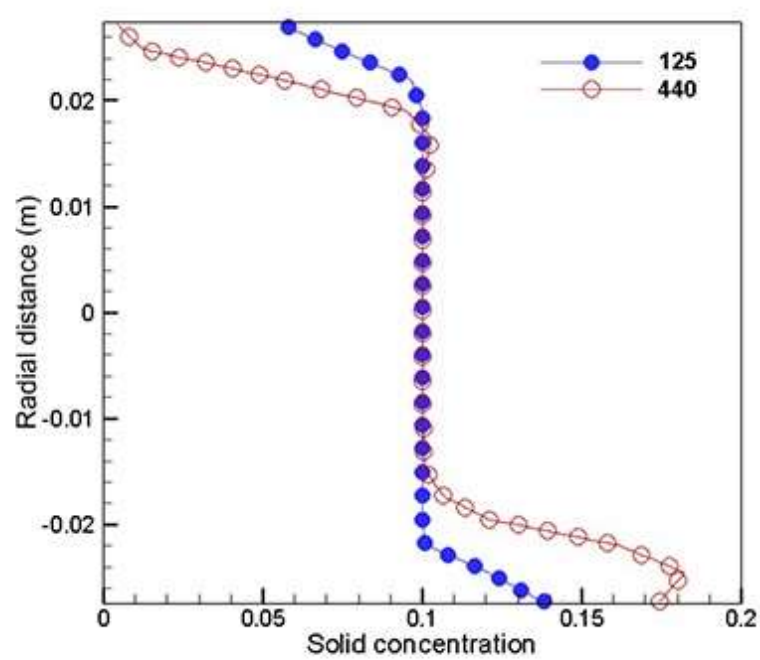

(a)

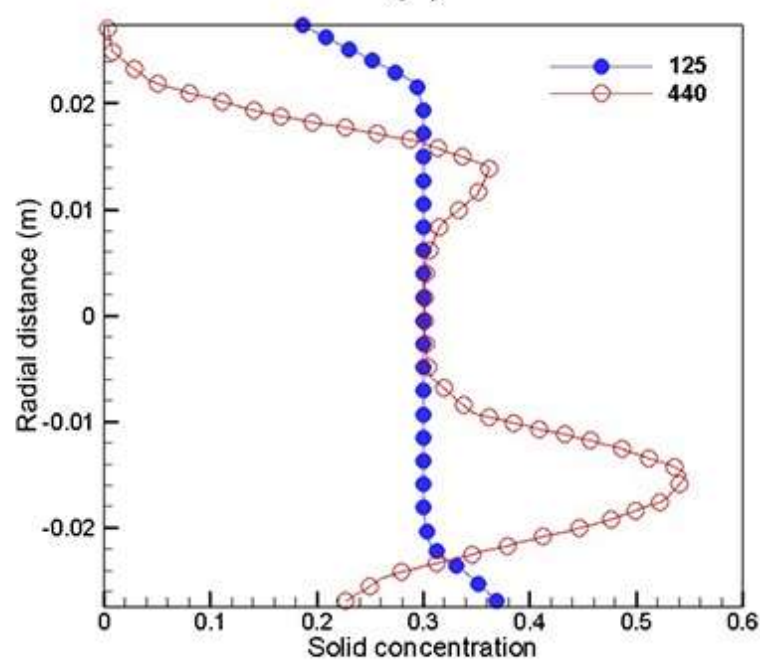

(c)

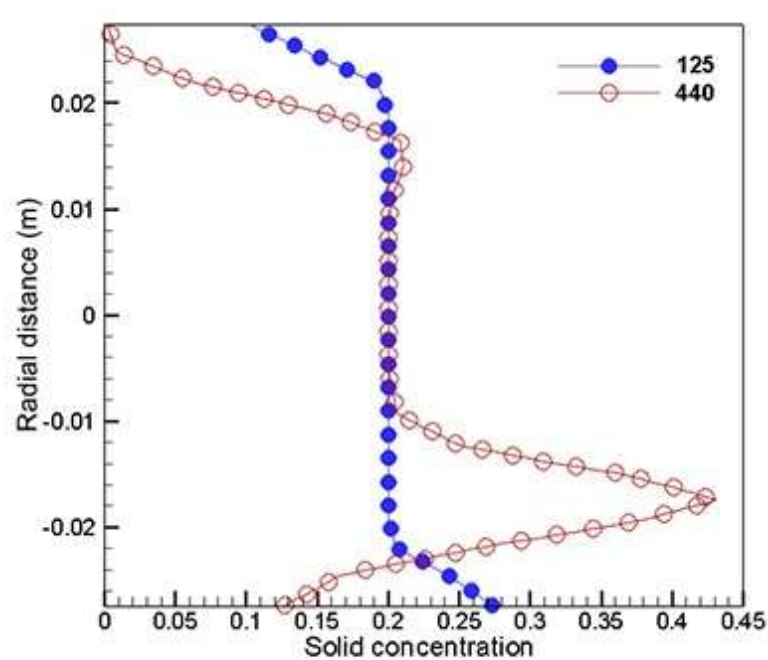

(b)

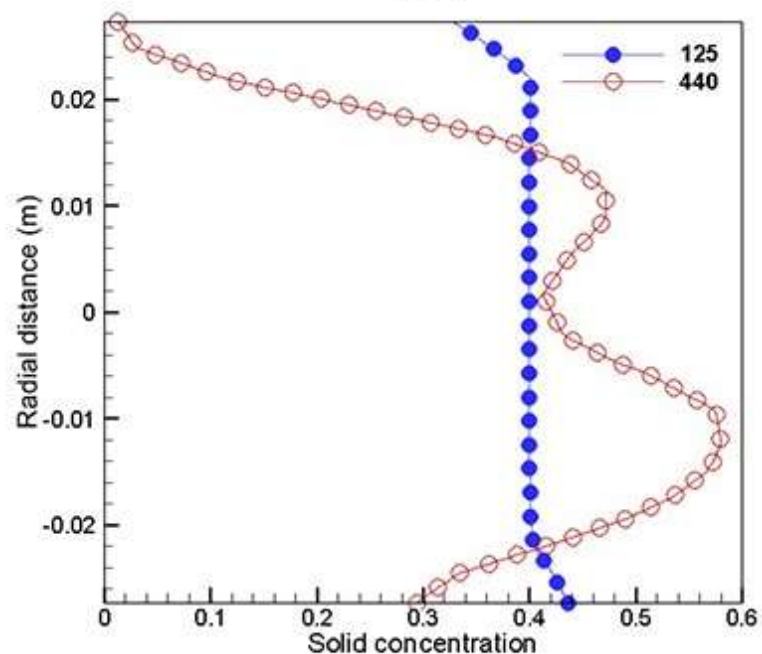

(d)

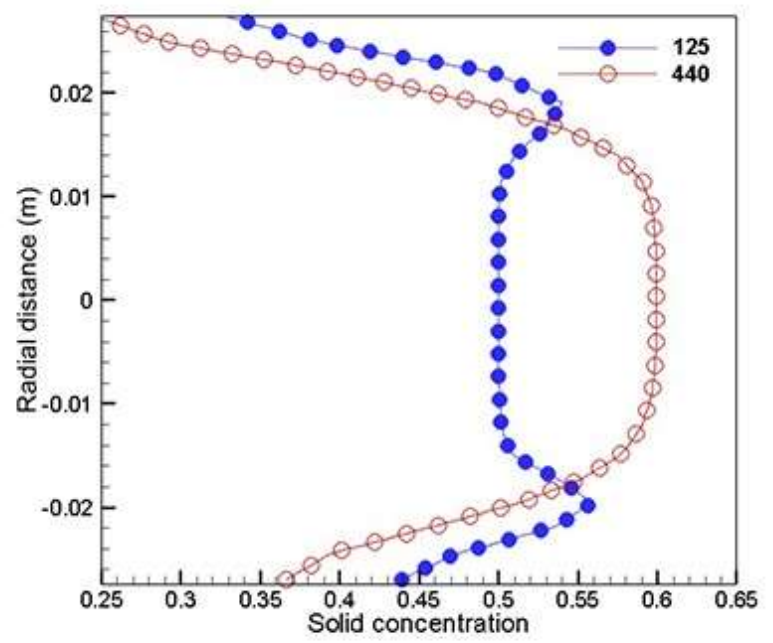

(e)

Figure 15. Solid concentration profiles in XY plane at X $=3.7$ m and $V_{m}=4 \mathrm{~ms}^{-1}$ (a) $C_{v f}=10 \%$, (b) $C_{v f}=20 \%$, (c) $C_{v f}=30 \%$, (d) $C_{v f}=40 \%$, and (e) $C_{v f}=50 \%$ 


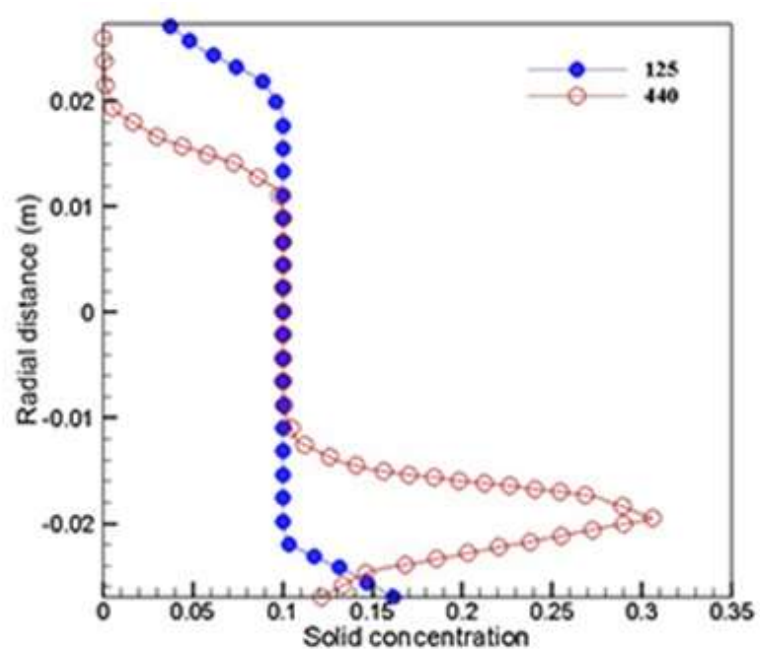

(a)

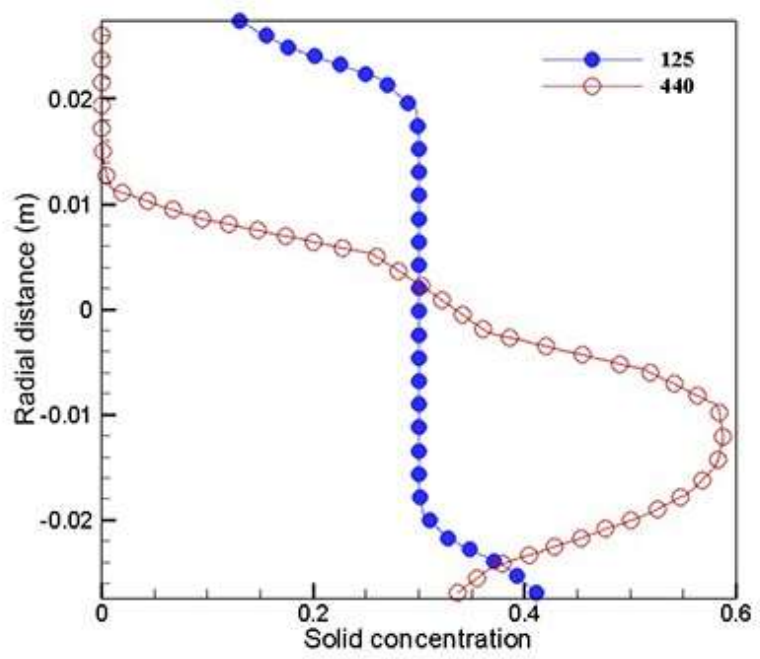

(c)

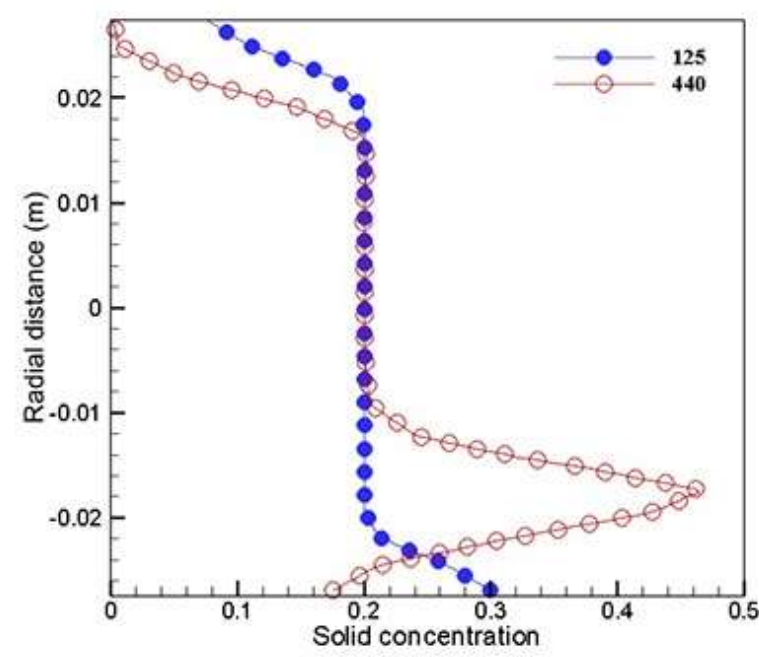

(b)

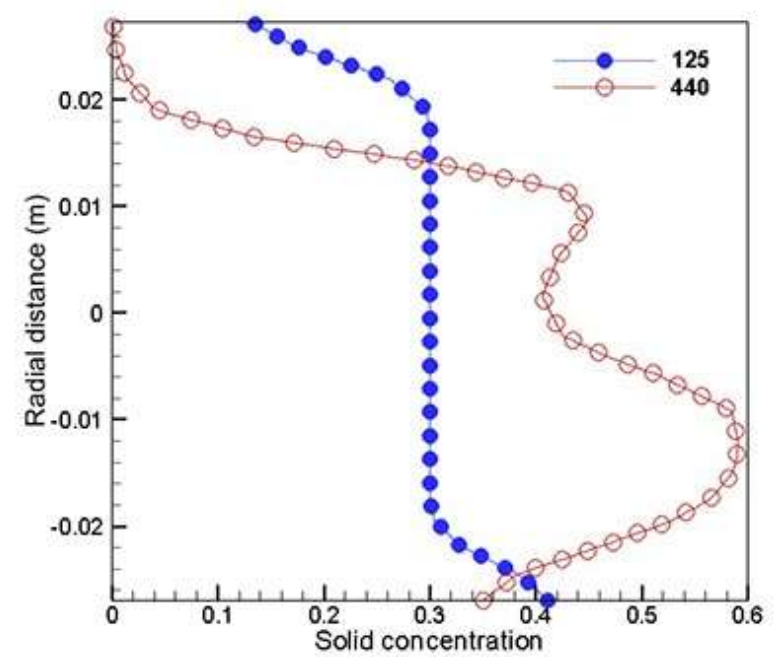

(d)

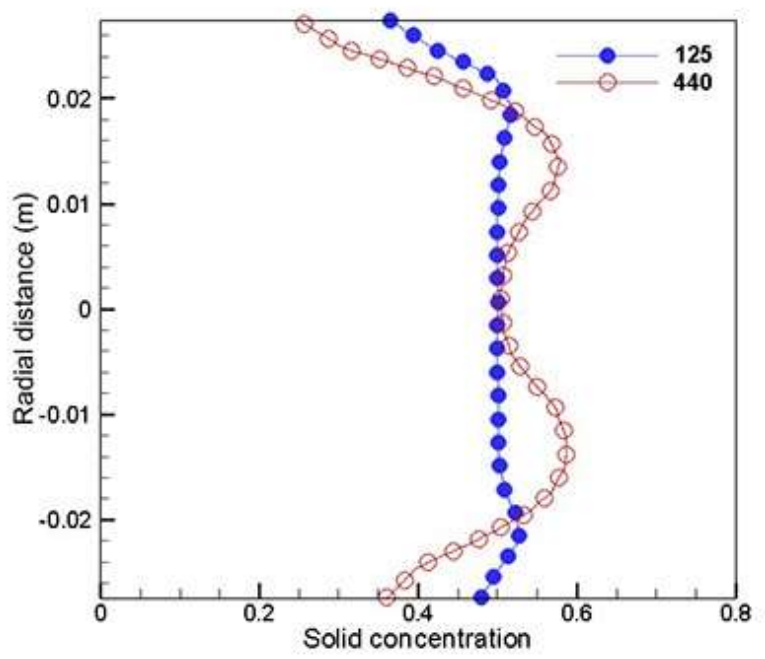

(e)

Figure 16. Solid concentration profiles in XY plane at $\mathrm{X}=3.7 \mathrm{~m}$ and $V_{m}=5 \mathrm{~ms}^{-1}$ (a) $C_{v f}=10 \%$, (b) $C_{v f}=20 \%$, (c) $C_{v f}=30 \%$, (d) $C_{v f}=40 \%$, and (e) $C_{v f}=50 \%$ 


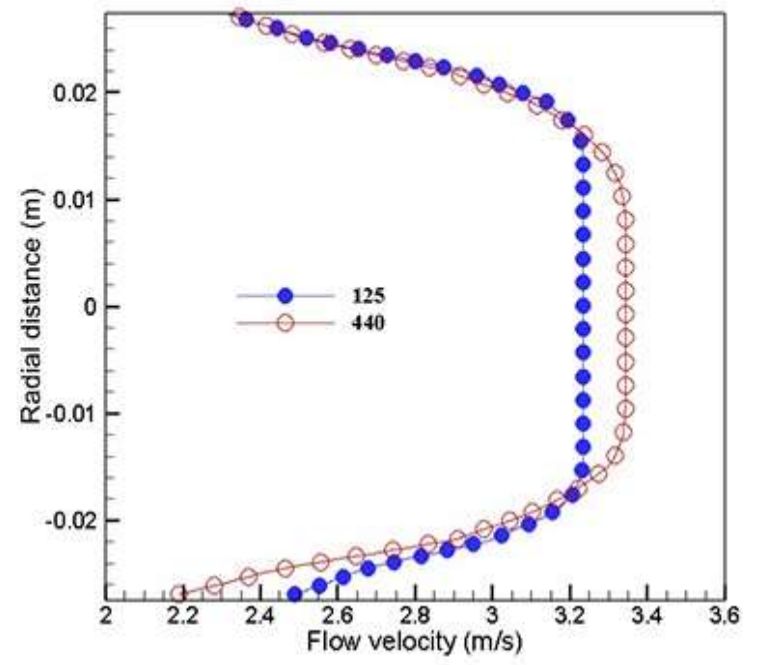

(a)

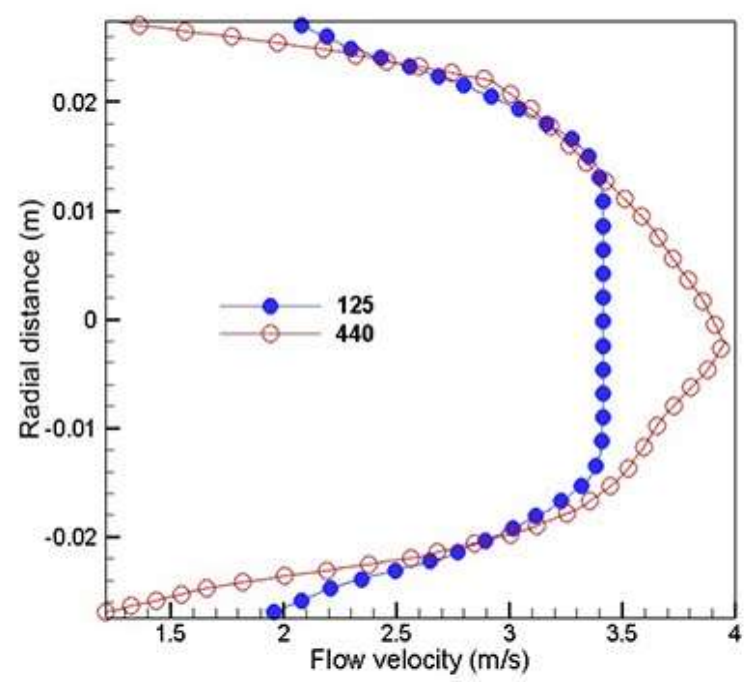

(c)

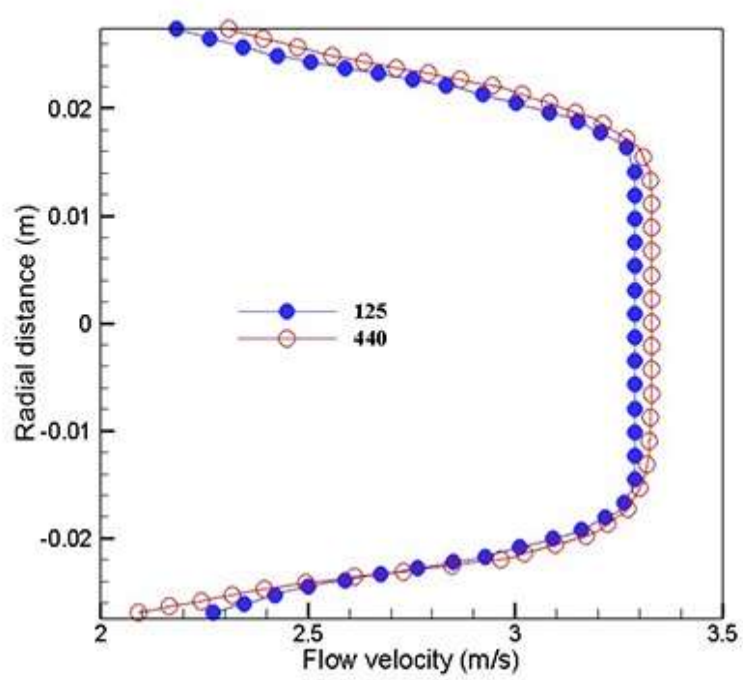

(b)

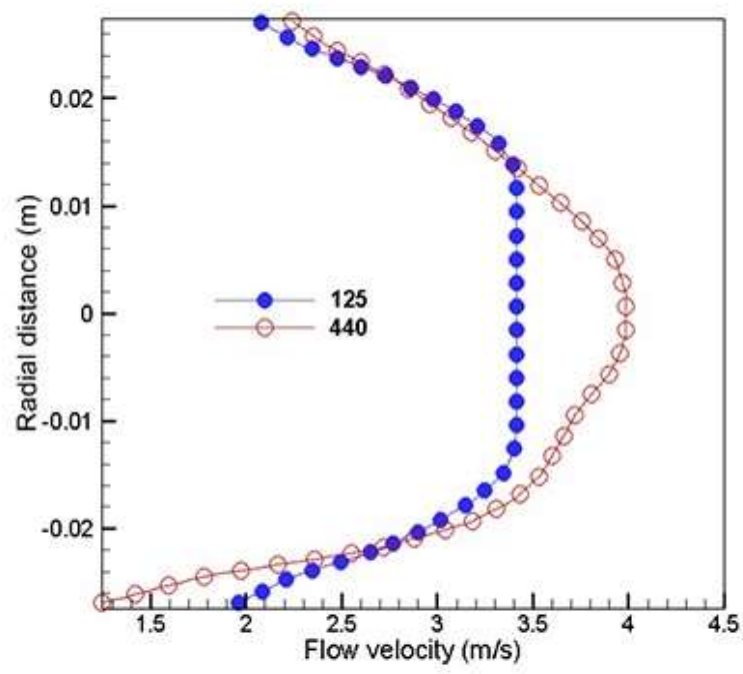

(d)

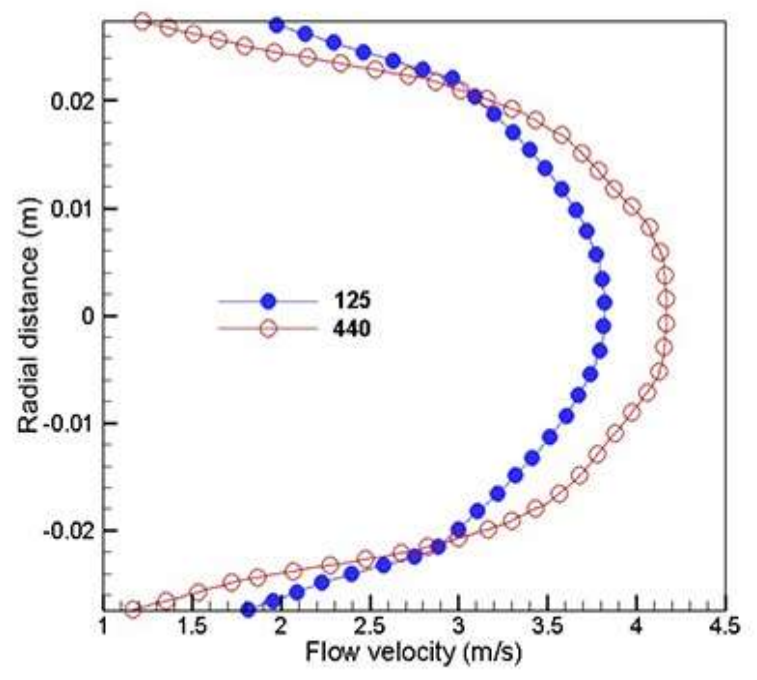

(e)

Figure 17. Solid velocity profiles in XY plane at X $=3.7 \mathrm{~m}$ and $V_{m}=3 \mathrm{~ms}^{-1}$ (a) $C_{v f}=10 \%$, (b) $C_{v f}=20 \%$, (c) $C_{v f}=30 \%$, (d) $C_{v f}=40 \%$, and (e) $C_{v f}=50 \%$ 


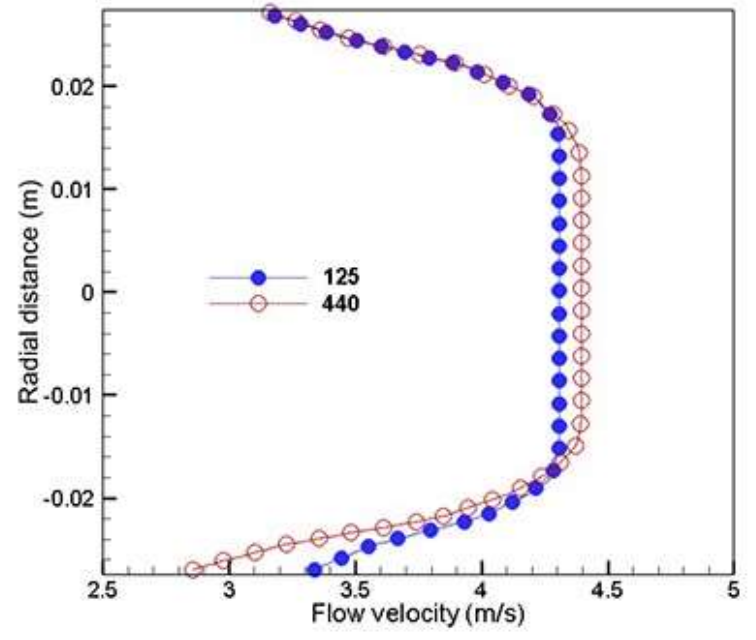

(a)

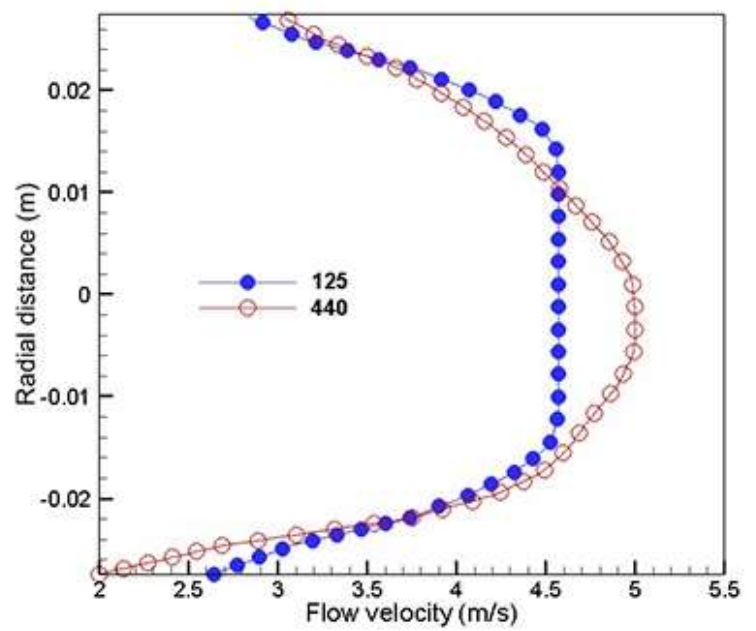

(c)

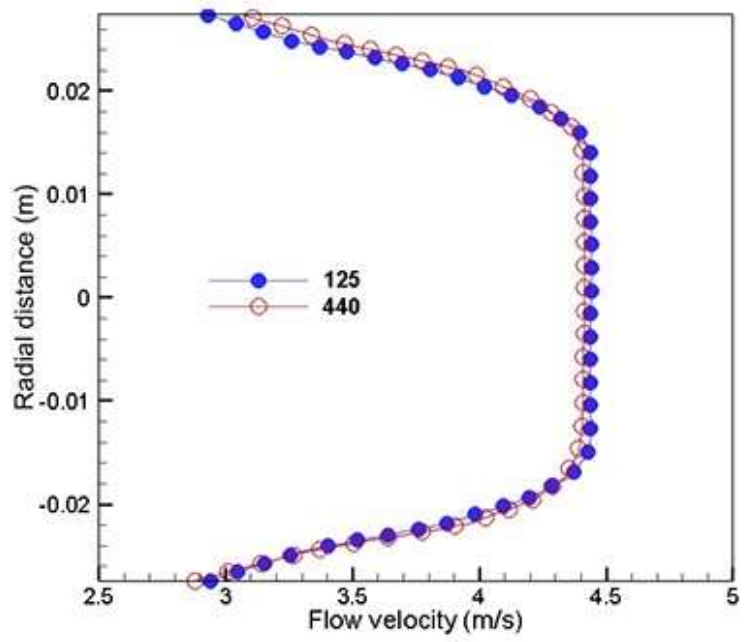

(b)

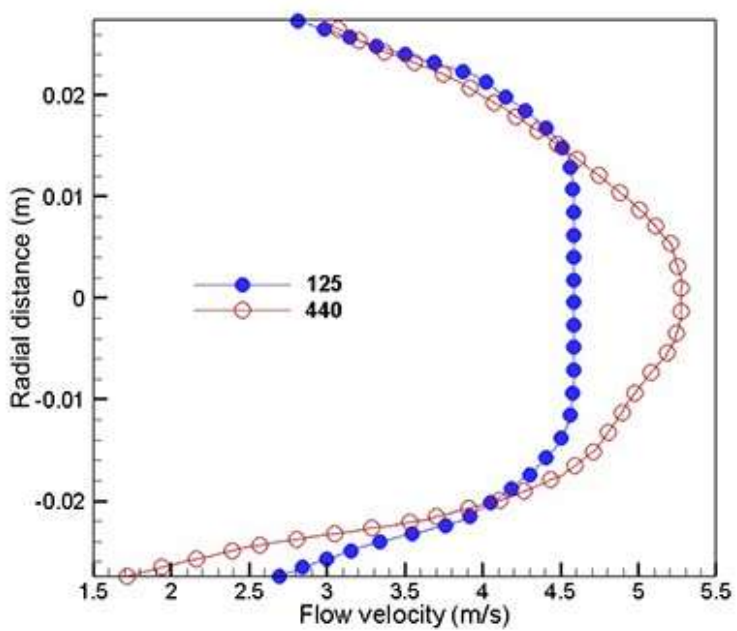

(d)

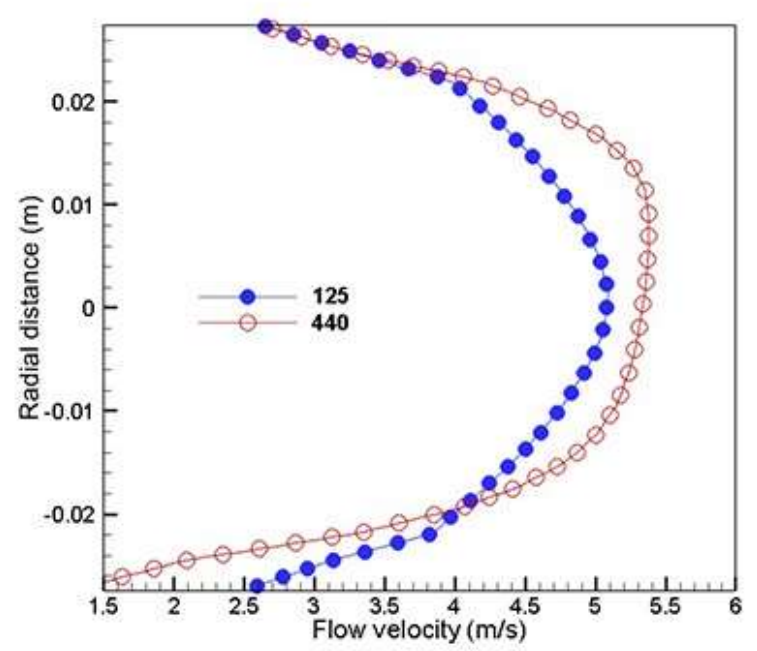

(e)

Figure 18. Solid velocity profiles in XY plane at X $=3.7 \mathrm{~m}$ and $V_{m}=4 \mathrm{~ms}^{-1}$ (a) $C_{v f}=10 \%$, (b) $C_{v f}=20 \%$, (c) $C_{v f}=30 \%$, (d) $C_{v f}=40 \%$, and (e) $C_{v f}=50 \%$ 


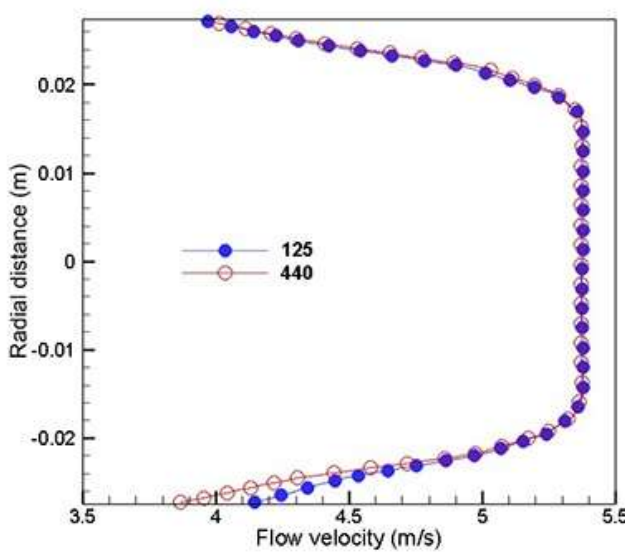

(a)

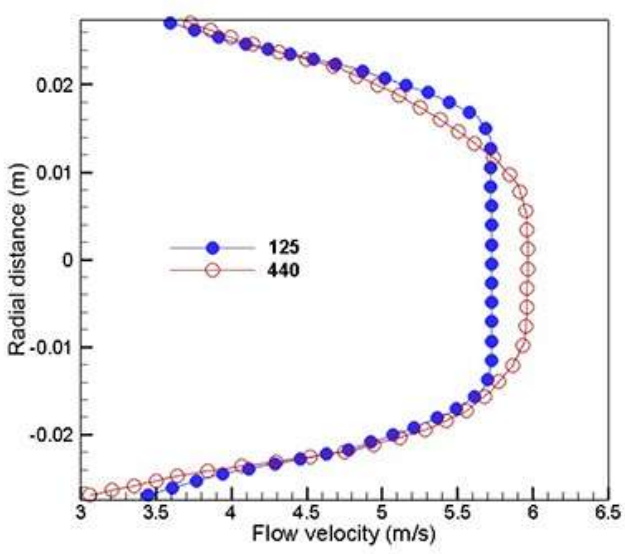

(c)

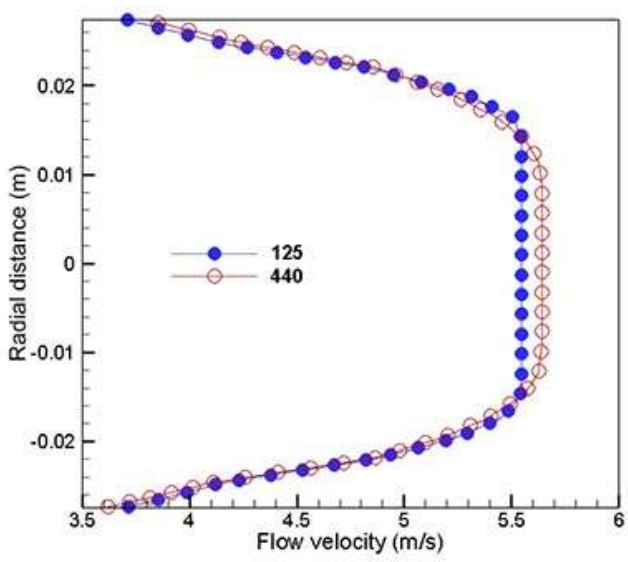

(b)

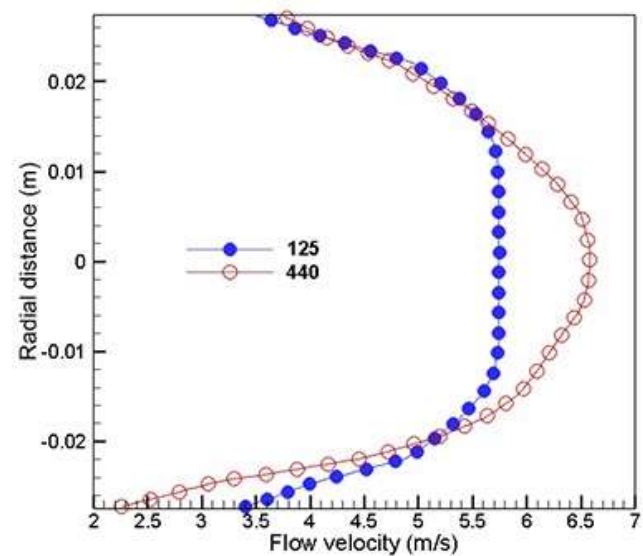

(d)

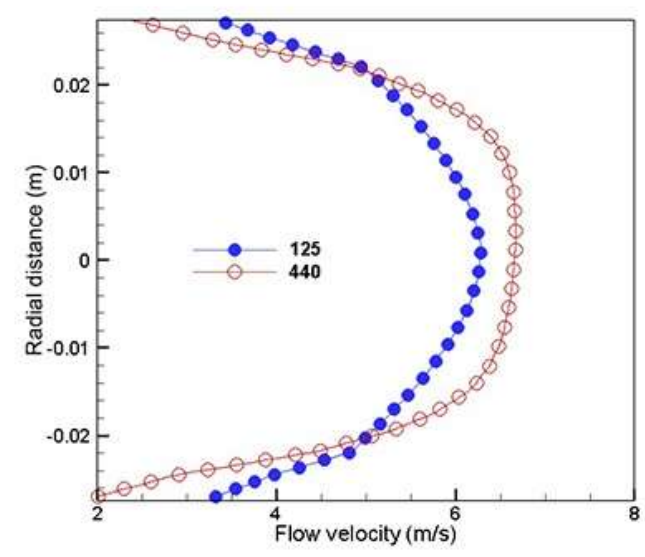

(e)

Figure 19. Solid velocity profiles in XY plane at $\mathrm{X}=3.7 \mathrm{~m}$ and $V_{m}=5 \mathrm{~ms}^{-1}$ (a) $C_{v f}=10 \%$, (b) $C_{v f}=20 \%$, (c) $C_{v f}=30 \%$, (d) $C_{v f}=40 \%$, and (e) $C_{v f}=50 \%$

\section{Pressure drop}

Pressure drop is the key parameter for designing the slurry pipeline systems. The pressure drop per meter length at different velocity and concentration range is depicted in the Figure 20(a) and 20 (b). It is found that pressure drop increases with increase in velocity at all efflux concentration range. The pressure drop finding for small sized solid particulate slurry pipeline is very less as compared to the pressure drop of large sized particulate slurry pipeline. The ample change in pressure drop found at solid concentration, $C_{v f}=40-50 \%$ for both sized solid particulates due to increased turbulence that results in damage and severe losses in the pipeline. For solid particulate $125 \mu \mathrm{m}$ and $440 \mu \mathrm{m}$ the percentage change in pressure drop w.r.t. solid concentration at $C_{v f}=10 \%$ is 
depicted in the Table 1 and Table 2 respectively. Table 3 depicts the percentage change in pressure drop w.r.t. 125 $\mu \mathrm{m}$ solid particulates and it is found that the percentage change in pressure drop for $440 \mu \mathrm{m}$ solid particulate is very high i.e. $170 \%$ compared to the pressure drop of $125 \mu \mathrm{m}$ solid particulates at $V_{m}=5 \mathrm{~ms}^{-1}$ and $C_{v f}=50 \%$. It has been found that up to $30 \%$ solid concentration, large sized solid particulate can be used but at the same time, it is also observed that the pressure drop rises suddenly as solid concentration increases beyond $30 \%$ and will require more power. Additionally, the increase in pressure drop also affects the life of slurry pipeline system. Therefore, it is recommended that first reduce the size of solid particulate as small as possible by crushing and grinding in order to make the slurry pipeline system more efficient. The increased pressure drop also increase the power consumption requirement. Hence, the comparative analysis of pressure drop for solid particulate size proves the practical utility and high designing capability of slurry pipeline system.

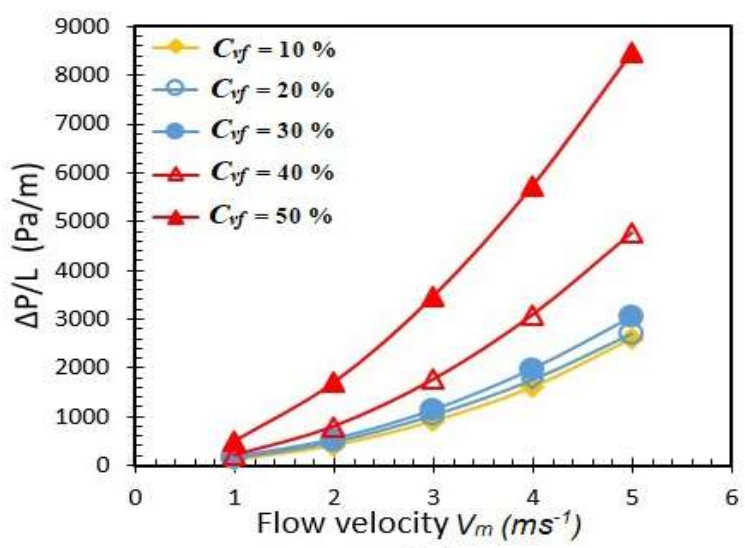

(a)

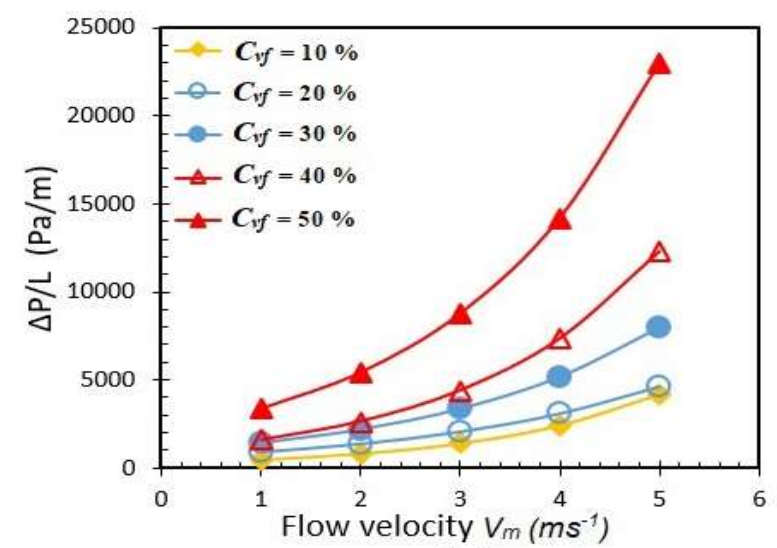

(b)

Figure 20. Pressure drop per meter length vs Flow Velocity at all solid concentration (a) $d_{p}=125 \mu \mathrm{m}$ and (b) $\mathrm{d}_{\mathrm{p}}=440 \mu \mathrm{m}$

Table1. Percentage change in pressure drop for $125 \mu \mathrm{m}$ solid particulate at different velocity and solid concentrations

\begin{tabular}{|c|c|c|c|c|}
\hline \multirow{2}{*}{$\boldsymbol{V}_{\boldsymbol{m}}\left(\mathbf{m s}^{-\mathbf{1}}\right)$} & \multicolumn{4}{|c|}{ Pressure drop change in (\%) w.r.t. solid concentration at $\boldsymbol{C}_{\boldsymbol{v} f}=\mathbf{1 0} \%$} \\
\cline { 2 - 5 } & At $\boldsymbol{C}_{\boldsymbol{v} \boldsymbol{f}}=\mathbf{2 0} \%$ & At $\boldsymbol{C}_{\boldsymbol{v} \boldsymbol{f}}=\mathbf{3 0} \%$ & At $\boldsymbol{C}_{\boldsymbol{v} \boldsymbol{f}}=\mathbf{4 0} \%$ & At $\boldsymbol{C}_{\boldsymbol{v} \boldsymbol{f}}=\mathbf{5 0 \%}$ \\
\hline 3 & 14 & 25 & 95 & 285 \\
\hline 4 & 10 & 24 & 93 & 258 \\
\hline 5 & 4 & 17 & 83 & 226 \\
\hline
\end{tabular}

Table 2. Percentage change in pressure drop for $440 \mu \mathrm{m}$ solid particulate at different velocity and solid concentrations

\begin{tabular}{|c|c|c|c|c|}
\hline \multirow{2}{*}{$\boldsymbol{V}_{\boldsymbol{m}}\left(\mathbf{m s}^{-\mathbf{1}}\right)$} & \multicolumn{4}{|c|}{ Pressure drop change in (\%) w.r.t. solid concentration at $\boldsymbol{C}_{\boldsymbol{v} \boldsymbol{f}}=\mathbf{1 0} \%$} \\
\cline { 2 - 5 } & At $\boldsymbol{C}_{\boldsymbol{v} \boldsymbol{f}}=\mathbf{2 0} \%$ & At $\boldsymbol{C}_{\boldsymbol{v} \boldsymbol{f}}=\mathbf{3 0} \%$ & At $\boldsymbol{C}_{\boldsymbol{v} \boldsymbol{f}}=\mathbf{4 0 \%}$ & $\mathbf{A t} \boldsymbol{C}_{\boldsymbol{v} \boldsymbol{f}}=\mathbf{5 0} \%$ \\
\hline 3 & 48 & 140 & 214 & 525 \\
\hline 4 & 27 & 113 & 202 & 484 \\
\hline 5 & 9 & 89 & 192 & 445 \\
\hline
\end{tabular}

Table 3. Percentage change in pressure drop for different solid particulate size $(125 \mu \mathrm{m}$ and $440 \mu \mathrm{m})$ at different velocity and solid concentration

\begin{tabular}{|c|c|c|c|c|c|c|c|c|c|c|c|c|c|c|c|}
\hline \multirow{2}{*}{$\begin{array}{l}V_{m} \\
\left(\mathrm{~ms}^{-1}\right)\end{array}$} & \multicolumn{2}{|c|}{$\begin{array}{c}\Delta \mathrm{P} / \mathrm{L}(\mathrm{Pa} / \mathrm{m}) \text { at } \\
C_{y f}=10 \%\end{array}$} & \multirow{2}{*}{$\begin{array}{c}\% \\
\text { change }\end{array}$} & \multicolumn{2}{|c|}{$\begin{array}{c}\Delta \mathrm{P} / \mathrm{L}(\mathrm{Pa} / \mathrm{m}) \text { at } \\
C_{V^{f}}=\mathbf{2 0} \%\end{array}$} & \multirow{2}{*}{$\begin{array}{c}\% \\
\text { change }\end{array}$} & \multicolumn{2}{|c|}{$\begin{array}{c}\Delta \mathrm{P} / \mathrm{L}(\mathrm{Pa} / \mathrm{m}) \text { at } \\
C_{V f}=\mathbf{3 0} \%\end{array}$} & \multirow{2}{*}{$\begin{array}{c}\% \\
\text { change }\end{array}$} & \multicolumn{2}{|c|}{$\begin{array}{c}\Delta \mathrm{P} / \mathrm{L}(\mathrm{Pa} / \mathrm{m}) \text { at } \\
C_{v f}=40 \%\end{array}$} & \multirow[t]{2}{*}{$\begin{array}{c}\% \\
\text { change }\end{array}$} & \multicolumn{2}{|c|}{$\begin{array}{c}\Delta \mathrm{P} / \mathrm{L}(\mathrm{Pa} / \mathrm{m}) \text { at } \\
C_{v^{f}}=\mathbf{5 0} \%\end{array}$} & \multirow{2}{*}{$\begin{array}{c}\% \\
\text { change }\end{array}$} \\
\hline & $125 \mu \mathrm{m}$ & $440 \mu \mathrm{m}$ & & $125 \mu \mathrm{m}$ & $440 \mu \mathrm{m}$ & & $125 \mu \mathrm{m}$ & $440 \mu \mathrm{m}$ & & $125 \mu \mathrm{m}$ & $440 \mu \mathrm{m}$ & & $125 \mu \mathrm{m}$ & $440 \mu \mathrm{m}$ & \\
\hline 3 & 901.232 & 1399.443 & 55 & 1031.28 & 2071.91 & 100 & 1130.81 & 3349 & 196 & 1757.506 & 4392.75 & 150 & 3466.21 & 8749.08 & 150 \\
\hline 4 & 1599.369 & 2426.801 & 52 & 1761.137 & 3088.77 & 75 & 1976.3 & 5166.3 & 161 & 3080.012 & 7345.27 & 140 & 5729.25 & 14167.5 & 150 \\
\hline 5 & 2599.123 & 4208.364 & 62 & 2709.005 & 4604.68 & 70 & 3050.24 & 7969.8 & 161 & 4759.335 & 12282.3 & 160 & 8460.19 & 22941.5 & 170 \\
\hline
\end{tabular}




\section{Vector representation}

Figure $21(a-b)$ and $22(a-b)$ depicts the vector representation of solid concentration and solid velocity in last one meter length of the pipeline for particulate size $(125 \mu \mathrm{m}$ and $440 \mu \mathrm{m})$ at $V_{m}=3 \mathrm{~ms}^{-1}$ and $C_{v f}=20 \%$ respectively. It has been observed that the small sized solid particulate moves in the pipe bottom as depicted in the Figure 21 (a). However, large sized particulate moves away from the pipe bottom due to near wall lift force as depicted in the Figure 21 (b). Figures 22 (a) and (b) depict that the small sized and large sized particulate exhibits maximum velocity in the centre of the pipeline and their velocity diminishes, when move from pipe centre to pipe wall due to viscous forces. Similar trend has been found at other all solid concentration range and flow velocities, hence not been shown here.

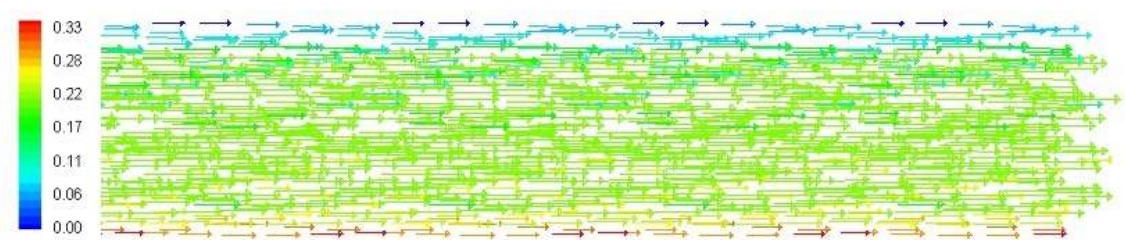

(a)

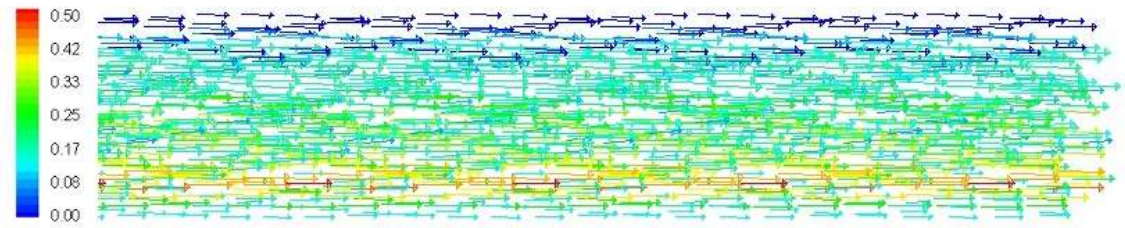

(b)

Figure 21. Vector representation of solid concentration in XY plane at $V_{m}=3 \mathrm{~ms}^{-1}$ and $C_{v f}=20 \%$ (a) $\mathrm{d}_{\mathrm{p}}=$ $125 \mu \mathrm{m}(\mathrm{b}) \mathrm{d}_{\mathrm{p}}=440 \mu \mathrm{m}$,

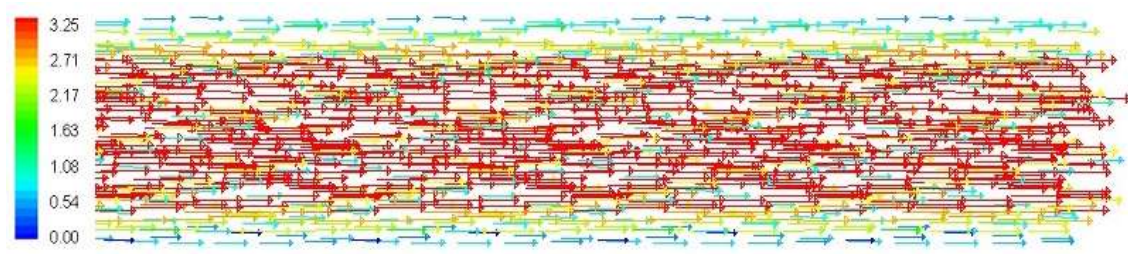

(a)

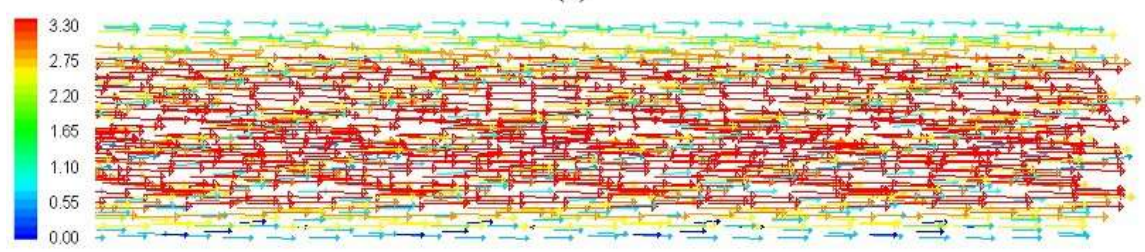

(b)

Figure 22. Vector representation of solid velocity in XY plane at $V_{m}=3 \mathrm{~ms}^{-1}$ and $C_{v f}=20 \%$ (a) $\mathrm{d}_{\mathrm{p}}=125 \mu \mathrm{m}$ (b) $\mathrm{d}_{\mathrm{p}}=440 \mu \mathrm{m}$

\section{MODEL VALIDATION}

The present developed computational model for $125 \mu \mathrm{m}$ and $440 \mu \mathrm{m}$ is validated with the available experimental data of Kaushal et al. (2007) in the literature. Figure 23(a) depicts the validation of the present study with the available experimental data at $C_{v f}=50 \%$ for $125 \mu \mathrm{m}$ particulate size. Figure 23(b) depicts the validation of the present study with the available experimental data at $C_{v f}=10 \%$ for $440 \mu \mathrm{m}$ particulate size. It is found that the present computational results using Eulerian two-phase model with RNG K- $\varepsilon$ turbulence closure are in synchronism with the experimental data. 


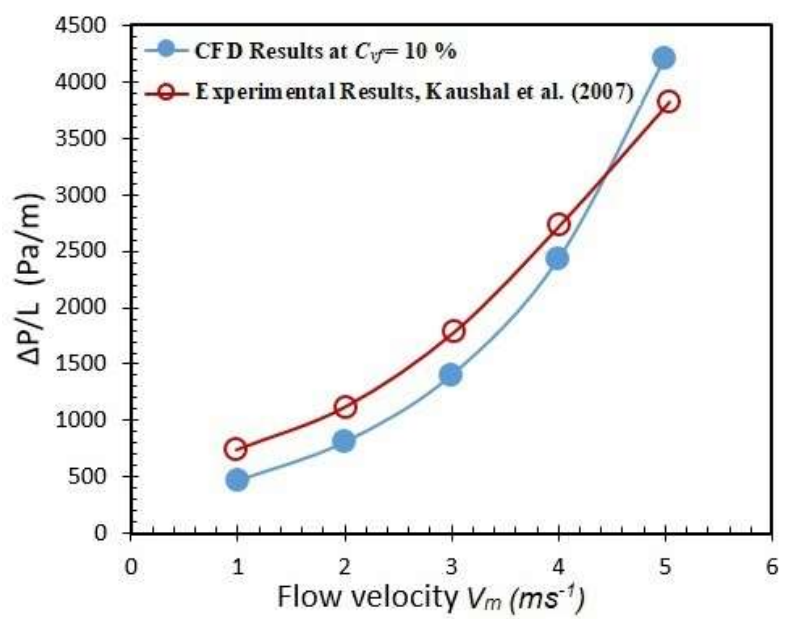

(a)

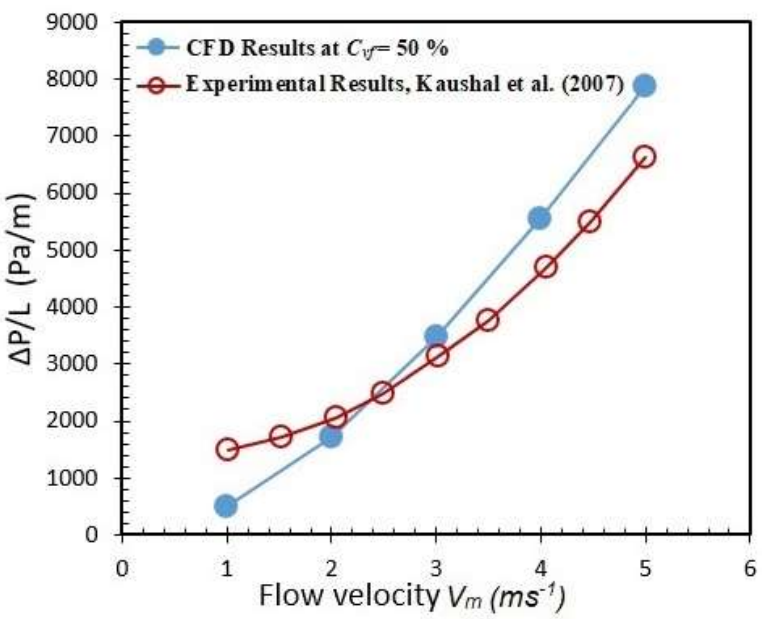

(b)

Figure 23. Validation of computational model (a) for particulate size $125 \mu \mathrm{m}$ at $C_{v f}=50 \%$ and (b) for particulate size $440 \mu \mathrm{m}$ at $C_{v f}=10 \%$

\section{CONCLUSIONS}

Based on the investigations on $0.0549 \mathrm{~m}$ diameter glass -beads slurry pipeline using commercial CFD software for different efflux concentrations and slurry velocities, the following conclusions have been drawn:

- It is observed that Eulerian model using RNG k- $\varepsilon$ turbulence closure gives the more appropriate and meticulous predictions of the pressure drop for chosen range of solid concentration, flow velocity and particulate size.

- The high concentration zone is situated near the pipe bottom for small sized particulates at all velocities and all efflux solid concentration except at $\left(\mathrm{C}_{v f}=50 \%\right)$. Whereas, the solid concentration zone for large sized particulates is situated away from the pipe bottom at all velocities and all efflux solid concentration range.

- At higher solid concentration $\left(C_{v f}=50 \%\right)$, the momentum exchange between the solid particulates increases and enhance the turbulence mixing that results the glass beads particulates shift around the pipe centre.

- The maximum velocity region of small sized and large sized particulates is situated at the pipe centre at all velocity and solid concentration range.

- For $440 \mu \mathrm{m}$ solid particulates, the velocity contours are asymmetrical about the centre at the flow velocity, $V_{m}=3-4 \mathrm{~ms}^{-1}$ and solid concentration range, $C_{v f}=30-40 \%$. However, the velocity contours are symmetrical for $125 \mu \mathrm{m}$ at all velocity and solid concentration.

- The distributions of glass beads concentration are found flatten in nature at low solid concentration, which in turn becomes parabolic at higher solid concentration range for both sized solid particulates.

- Pressure drop increases for both $125 \mu \mathrm{m}$ and $440 \mu \mathrm{m}$ solid particulates with increase in velocity at all solid concentration range.

- $\quad$ Pressure drop abruptly increases for both sized solid particulates in the solid concentration range $C_{v f}=40$ $50 \%$.

- $\quad$ Pressure drop for $440 \mu \mathrm{m}$ solid particulates is found higher as compared to the pressure drop of $125 \mu \mathrm{m}$ solid particulates.

- The obtained results of predicted pressure drop are observed to be in synchronism with the experiment results.

The comparison of the solid particulate size using Eulerian multiphase RNG k- $\varepsilon$ turbulence closure proves the practical utility and high designing capability of slurry pipeline system. 
Journal of Thermal Engineering, Research Article, Vol. 7, No. 1, pp.220-239 , January, 2021

\section{NOMENCLATURE}

$C_{v f} \quad$ Efflux concentration (by volume)

D Diameter of pipe, $m$

$\mathrm{d}_{\mathrm{s}} \quad$ Particle diameter, $\mu \mathrm{m}$

g Acceleration due to gravity, $\mathrm{m} / \mathrm{s}^{2}$

$\overrightarrow{v_{s}} \quad$ Velocity of solid phase, $\mathrm{m} / \mathrm{s}$

$\overrightarrow{v_{f}} \quad$ Velocity of fluid phase, $\mathrm{m} / \mathrm{s}$

$\mathrm{C}_{\mathrm{vm}} \quad$ Coefficient of virtual mass

$\rho \quad$ Mass density, $\mathrm{kg} / \mathrm{m}^{3}$

$\rho_{\mathrm{f}} \quad$ Mass density for fluid phase, $\mathrm{kg} / \mathrm{m}^{3}$

$\rho_{\mathrm{s}} \quad$ Mass density for solid phase, $\mathrm{kg} / \mathrm{m}^{3}$

$\mathrm{C}_{\mathrm{L}} \quad$ Lift force

$\mathrm{V}_{\mathrm{m}} \quad$ Mean flow velocity, $\mathrm{m} / \mathrm{s}$

$\operatorname{Re}_{\mathrm{s}} \quad$ Relative Reynold number between solid and fluid phase

$\overline{\bar{I}} \quad$ Identity tensor

$\lambda_{\mathrm{s}} \quad$ Bulk viscosity of solid phase

$\overline{\tau_{f}} \quad$ viscous stress tensor for fluid phase

$\mathrm{g}_{\mathrm{o}, \mathrm{ss}} \quad$ Radial distribution function

$\mu_{\mathrm{s}} \quad$ Shear viscosity for solid phase, Pa-s

$\mu_{\mathrm{f}} \quad$ Shear viscosity for fluid phase, Pa-s

$\mu_{\mathrm{s}, \mathrm{col}} \quad$ collisional viscosity

$\mu_{\mathrm{s}, \mathrm{kin}} \quad$ kinetic viscosity

$\mu_{\mathrm{s}, \mathrm{fr}} \quad$ frictional viscosity

$\mathrm{C}_{\mathrm{D}} \quad$ Drag coefficient

$\mathrm{e}_{\mathrm{ss}} \quad$ Restitution coefficient

$\Theta_{s} \quad$ Granular temperature

$\mathrm{I}_{2 \mathrm{D}} \quad$ Second invariant strain rate tensor for solid phase

$\mathrm{K}_{\mathrm{sf}} \quad$ Inter-phasial momentum exchange coefficient

$\mathrm{V}_{\mathrm{r}, \mathrm{s}} \quad$ Terminal velocity for solid phase, $\mathrm{ms}^{-1}$

Greek symbols

$\alpha_{\mathrm{s}, \max } \quad$ Static settled concentration,

$\alpha_{s} \quad$ Solid phase concentration

$\alpha_{f} \quad$ Liquid phase concentration

Subscripts

f Refers to fluid

s Refers to solid

\section{REFERENCES}

[1] Colwell JM, Shook CA. The entry length for slurries in horizontal pipeline flow. Can J Chem Eng 1988; 66(5): 714-720. https://doi.org/10.1002/cjce.5450660503.

[2] Turian RM, Hsu FL, Selim MS. Friction losses for flow of slurries in pipeline bends, fittings, and valves. Particul Sci Technol 1983; 1(4): 365-392. https://doi.org/10.1080/02726358308906383.

[3] Matousek V. Pressure drops and flow patterns in sand-mixture pipes. Exp Therm Fluid Sci 2002; 26(6): 693-702. https://doi.org/10.1016/S0894-1777(02)00176-0.

[4] Krampa-Morlu FN, Bergstrom DJ, Bugg JD, Sanders RS, Schaan J. Numerical simulation of dense coarse particle slurry flows in a vertical pipe. In 5th Int Conf Multiphase flow, ICMF 2004; 4: 460. 
[5] Kraft M. Modelling of Particulate Processes. KONA Powder Part J 2005; 23:18-35. https://doi.org/10.14356/kona.2005007.

[6] Kaushal DR, Tomita Y. Experimental investigation for near-wall lift of coarser particles in slurry pipeline Using $\gamma$-ray densitometer. Powder Techno, 2007; 172(3): 177-187. https://doi.org/10.1016/j.powtec.2006.11.020.

[7] Kumar U, Singh SN, Seshadri V. Prediction of flow characteristics of bimodal slurry in horizontal pipe flow. Particul Sci Technol 2008; 26(4): 361-379. https://doi.org/10.1080/02726350802084564.

[8] Lin CX, Ebadian MA. A numerical study of developing slurry flow in the entrance region of a horizontal pipe. Comput Fluids 2008; 37(8): 965-974. https://doi.org/10.1016/j.compfluid.2007.10.008.

[9] Chandel S, Singh SN, Seshadri V. Transportation of high concentration coal ash slurries through pipelines. Int Archive Appl Sci Tech 2010; 1: 1-9.

[10] Chandel S, Seshadri V, Singh SN. Effect of additive on pressure drop and rheological characteristics of fly ash slurry at high concentration. Particul Sci Technol 2009; 27(3): 271-284. https://doi.org/ $10.1080 / 02726350902922036$.

[11] Naik HK, Mishra MK, Rao KU. Influence of chemical reagents on rheological properties of fly ash-water slurry at varying temperature environment. Coal Combus Gasification Products 2011; 3: 83-93.

[12] Senapati PK, Mishra BK, Parida BK. Analysis of friction mechanism and homogeneity of suspended load for high concentration fly ash \& bottom ash mixture slurry using rheological and pipeline experimental data. Powder Technol 2013; 250: 154-163. https://doi.org/10.1016/j.powtec.2013.10.014.

[13] Jiang YY, Zhang P. Numerical investigation of slush nitrogen flow in a horizontal pipe. Chem Eng Sci 2012; 73: 169-180. https://doi.org/10.1016/j.ces.2012.01.027.

[14] Kaushal DR, Thinglas T, Tomita Y, Kuchii S, Tsukamoto H. CFD modeling for pipeline flow of fine particles at high concentration. Int J Multiphas Flow 2012; 43: 85-100. https://doi.org/10.1016/j.ijmultiphaseflow.2012.03.005.

[15] Kaushal DR, Kumar A, Tomita Y, Kuchii S, Tsukamoto H. Flow of mono-dispersed particles through horizontal bend. Int J Multiphas Flow 2013; 52: 71-91. https://doi.org/10.1016/j.ijmultiphaseflow.2012.12.009

[16] Nabil T, El-Sawaf I, El-Nahhas K. Sand-Water Slurry Flow Modelling in a Horizontal Pipeline by Computational fluid Dynamics Technique. Int Water Tech J 2014; 4(1): 13.

[17] Silva R, Garcia FAP, Faia Pedro MGM, Rasteiro M.G. Settling suspensions flow modelling: A review. KONA Powder Part J 2015; 32: 41-56. https://doi.org/10.14356/kona.2015009.

[18] Gopaliya MK, Kaushal DR. Analysis of effect of grain size on various parameters of slurry flow through pipeline using CFD. Particul Sci Technol 2015; 33(4): 369-384. https://doi.org/10.1080/02726351.2014.971988

[19] Pani GK, Rath P, Barik R, Senapati PK. The effect of selective additives on the rheological behavior of power plant ash slurry. Particul Sci Technol 2015; 33(4): 418-422. https://doi.org/10.1080/02726351.2014.990657

[20] Assefa KM, Kaushal DR. Experimental study on the rheological behaviour of coal ash slurries. J Hydrol Hydromech 2015; 63(4): 303-310.

[21] Swamy M, Díez NG, Twerda A. Numerical modelling of the slurry flow in pipelines and prediction of flow regimes. WIT Trans Eng Sci 2015; 89: 311-322.

[22] Wu D, Yang B, Liu Y. Pressure drop in loop pipe flow of fresh cemented coal gangue-fly ash slurry: Experiment and simulation. Adv Powder Technol 2015; 26(3): 920-927. https://doi.org/10.1016/j.apt.2015.03.009.

[23] Messa GV, Malavasi S. Improvements in the numerical prediction of fully-suspended slurry flow in horizontal pipes. Powder Technol 2015; 270: 358-367. https://doi.org/10.1016/j.powtec.2014.02.005.

[24] Gopaliya MK, Kaushal DR. Modeling of sand-water slurry flow through horizontal pipe using CFD. J Hydrol Hydromech 2016; 64(3): 261-272.

[25] Ofei TN, Ismail AY. Eulerian-Eulerian simulation of particle-liquid slurry flow in horizontal pipe. J Pet Eng 2016; 1-10. https://doi.org/10.1155/2016/5743471.

[26] Peng W, Cao X. Numerical simulation of solid particle erosion in pipe bends for liquid-solid flow. Powder Technol 2016; 294: 266-279. https://doi.org/10.1016/j.powtec.2016.02.030. 
[27] Kaushal DR, Kumar A, Tomita Y, Kuchii S, Tsukamoto H. Flow of Bi-modal Slurry through Horizontal Bend. KONA Powder Part J 2017; 34: 258-274. https://doi.org/10.14356/kona.2017016.

[28] Assefa, KM, Kaushal DR. A new model for the viscosity of highly concentrated multi-sized particulate $\begin{array}{llllll}\text { Bingham } & \text { slurries. } & \text { Particul } & \text { Sci } & \text { Technol 2017; } & \text { 35(1): }\end{array}$ https://doi.org/10.1080/02726351.2015.1131789.

[29] Melorie, AK, Kaushal DR. Experimental investigations of the effect of chemical additives on the rheological properties of highly concentrated iron ore slurries. KONA Powder Part J 2017; 2018001. https://doi.org/10.14356/kona.2018001.

[30] Naveh R, Tripathi NM, Kalman H. Experimental pressure drop analysis for horizontal dilute phase particle-fluid flows, Powder Technol 2017; 321: 355-368. https://doi.org/10.1016/j.powtec.2017.08.029.

[31] Singh JP, Kumar S, Mohapatra SK. Modelling of two-phase solid-liquid flow in horizontal pipe using computational fluid dynamics technique. Int J Hydrogen Energy 2017; 42(31): 20133-20137. d https://doi.org/oi:10.1016/j.ijhydene.2017.06.060.

[32] Launder BE, Spalding DB. The numerical computation of turbulent flows. In Numerical Prediction of Flow, Heat Transfer, Turbulence and Combustion, 1983; 96-116. https://doi.org/10.1016/B978-0-08030937

8.50016-7.

[33] Mohanty S, Parkash O, Arora R. Analytical and comparative investigations on counter flow heat exchanger using computational fluid dynamics. Journal of Computational \& Applied Research in Mechanical Engineering 2019; 10.22061/JCARME.2019.4665.1564.

[34] Mohanty S, Arora R, Parkash O. Performance prediction and comparative analysis for a designed, developed, and modeled counter flow heat exchanger using computational fluid dynamics. Computational Thermal Sciences: An International Journal 2019; 11(5):423-443. https://doi.org/ 10.1615/ComputThermalScien.2019028520

[35] Ahmed SU, Arora R, Parkash O. Flow characteristics of multiphase glass beads-water slurry through horizontal pipeline using Computational Fluid Dynamics." International Journal of Automotive and Mechanical Engineering 2019; 16(2): 6605-6623.

[36] Ahmed SU, Arora R, Parkash O. Prediction of Flow Parameters of Glass Beads-Water Slurry flow through horizontal Pipeline using Computational Fluid Dynamics. Jordan Journal of Mechanical \& Industrial Engineering 2018; 12(3):197-213.

[37] Parkash O, Kumar A, Sikarwar BS. CFD modeling of commercial slurry flow through horizontal pipeline. In Advances in Interdisciplinary Engineering 2019; 153-162. Springer, Singapore. https://doi.org/10.1007/978-981-13-6577-5_16.

[38] Ahmed SU, Arora R, Parkash O. Numerical investigations on flow characteristics of sand-water slurry through horizontal pipeline using computational fluid dynamics. J. Therm. Eng 2020; 6(2):128-139.

[39] Parkash O, Arora R. Flow characterization of multi-phase particulate slurry in thermal power plants using computational fluid dynamics. J Therm Eng 2020; 6(1):187-203. https://doi.org/10.18186/thermal.672785.

[40] Verma OP, Kumar A, Sikarwar BS. Numerical simulation and comparative analysis of pressure drop estimation in horizontal and vertical slurry pipeline. J. Mech. Eng. Sci.. 2020; 14(2):6610-24. https://doi.org/10.15282/jmes.14.2.2020.06.0518.

[41] Arora R, Arora R. Thermodynamic optimization of an irreversible regenerated brayton heat engine using modified ecological criteria. J Therm Eng 2020; 6(1): 28-42. https://doi.org/10.18186/thermal.671079.

[42] Kaushik SC, Kumar R, Arora R. Thermo-economic optimization and parametric study of an irreversible regenerative Brayton cycle. J Therm Eng 2016; 4(2):861-870. https://doi.org/10.18186/jte.70740.

[43] Dalkiliç AS, Cebi A, Celen A. Numerical analyses on the prediction of nusselt numbers for upward and downward flows of water in a smooth pipe: effects of buoyancy and property variations. J Therm Eng 2019; 5(3): 166-180. https://doi.org/10.18186/thermal.540367.

[44] Anil S, Dizman T, Celen A, Bilge D, Dalkılıç AS, Wongwises, S. CFD analysis of smoke and temperature control system of an indoor parking lot with jet fans. J Therm Eng 2015; 1(2): 116-130. https://doi.org/10.18186/jte.02276. 